\title{
Arginine: Appropriate Dose and Delivery Environment Makes It an Anticancer Molecule
}

\author{
Jyoti Shukla, V.S. Thakur and T.B. Poduval" \\ Immunology and Hyperthermia Section, Radiation Biology and Health Sciences Division, Bhabha Atomic Research \\ Centre, Trombay, Mumbai - 400 085, India
}

\begin{abstract}
The electrostatic attraction between the negatively charged components of cancer cells and the positively charged anticancer peptides (ACPs) is believed to play a role in selective disruption of cancer cell membrane. Since arginine (Arg), a cationic amino acid is the most prevalent in these ACPs; we hypothesized that Arg when delivered in saline environment at the pharmacological concentration could become an anticancer molecule. The effects of L-Arg and D-Arg on tumor cell lines were studied. The therapeutic ability of pharmacological doses of Arg in saving the mice from experimental tumors was also evaluated. Both the enantiomers of Arg and not the cationic amino acid L-lysine (L-Lys) or agmatine-sulphate, at $10 \mathrm{mM}$ concentration caused tumor cell clumping when treated in PBS. Arg delivered in PBS (Arg$\mathrm{P}$ ) and not in medium (Arg-M) up to $50 \mathrm{mM}$ caused extensive tumor cell membrane damage leading to its death. Arg at $150 \mathrm{mM}$ and above irrespective of chirality and incubation vehicle became an effective antitumor molecule against all the four cell lines tested. L-Arg was not toxic to normal cells like erythrocytes, lymphocytes, NIH 3 T3 cells when presented in PBS. Arg cured mice bearing solid tumor fibrosarcoma (FS) when delivered into the tumor either in PBS or medium and lymphosarcoma-ascitic (LSA) tumor when delivered intraperitoneally in PBS. Our studies indicate that Arg can be used for loco-regional tumor therapy with minimal damage to normal cells and the mechanism of anticancer action of Arg is not metabolically driven but through its chemical structure, dose and delivery environment.
\end{abstract}

Keywords: Arginine, loco-regional therapy, non-metabolic, anticancer, pharmacological dose, membrane damage, delivery environment.

\section{INTRODUCTION}

Arginine (Arg) is involved in a number of biosynthetic pathways that significantly influence carcinogenesis and tumor biology [1-4]. Arg and its metabolic products have been demonstrated to modulate immune, inflammatory and metabolic pathways and facilitate or inhibit the growth of the tumor [4-7]. Arg containing anticancer peptides (ACPs) have also been known to kill tumor cells by disrupting the cell membrane, through a non-metabolic process based on their structure. This anticancer property of ACPs eliminates cancer chemotherapy associated adverse side effects and the frequent development of multi-drug resistance [8-11]. Cancer cell membranes typically carry a net negative charge due to higher than normal expression of anionic molecules [11]. The electrostatic attraction between the negatively charged components of cancer and bacterial cell membrane and the positively charged ACPs and cationic antimicrobial peptides (CAPs) is believed to play a role in the strong binding and selective disruption of cancer and bacterial cell membrane, respectively $[8,9,11,12-15]$. ACPs have also

*Address correspondence to this author at the Immunology \& Hyperthermia Section, Radiation Biology \& Health Sciences Division, Bhabha Atomic Research Centre, Trombay, Mumbai-400 085, India; Tel: +91 22 25593865; Fax: +91 22 25505151; E-mail: tbpodu@barc.gov.in been demonstrated to be selective in killing tumor cells as cancer cell plasma and mitochondrial membrane potential are typically higher than those of normal cells [16]. Cationic amino acid Arg is commonly found in positively charged ACPs and CAPs. Arg oligomers of more than five amino acids were effective in interacting and entering the biological cells [12]. Arg-Gly-Asp (RGD) sequence not only possesses tumor targeting capacity, but also has tumor cytotoxic and invasiveness inhibition effects dependent on the blockage of alpha (v) integrin activity, which would make it more efficient in tumor targeting therapy [13, 17]. Arg has been shown to be present as molecular clusters in solutions and forms supramolecular assembly in phosphate buffer saline (PBS) in a dose dependent manner up to $0.5 \mathrm{M}$ and display a hydrophobic surface $[18,19]$. The clustering was dependent on the delivery environment of the Arg solution. Such hydrophobicity has been shown to enhance the antitumor and antimicrobial property of the peptides [11]. Considering the above, we hypothesized that either L-Arg or D-Arg when delivered at pharmacological doses at the tumor site depending on the delivery environment could become an effective anticancer molecule [20]. Since drugs are delivered in a saline environment, the effects of pharmacological doses of Arg in PBS environment on its ability to kill tumor cells were studied, both in vitro and in vivo conditions. The current work revolves around the anticancer nature of Arg based on its chemical structure and delivery environment, which has not been studied so far. 


\section{MATERIALS AND METHODS}

\section{Mice}

Protocols for the animal studies described here were approved by the Bhabha Atomic Research Centre Animal Ethics Committee which is in accordance with the guidelines laid down by the Committee for the Purpose of Control and Supervision of Experiments on Animals, Government of India. Swiss/Bh inbred male albino mice, 8-10 weeks old and weighing between 26-28 g were reared in the animal house facility of the Bhabha Atomic Research Centre [21]. They were acclimatized to room temperature at $23.1 \pm 1{ }^{\circ} \mathrm{C}$, relative humidity of $50 \pm 10 \%$ and a $12 \mathrm{~h}$ dark/light cycle for one week before the start of the experiment. The animals were fed with standard laboratory diet and had free access to drinking water.

\section{Cell Lines and Culture}

A549 (Highly metastatic, human lung carcinoma), INT407 (human embryonic intestine), MCF7 (Human breast adenocarcinoma), EL4 ( $\mathrm{T}$ cell lymphoma of C57BL/6 mouse) and NIH 3T3 (Swiss mouse fibroblast) were obtained from National Centre for Cell Sciences, Pune, India. Lymphosarcoma ascites (LSA) and Fibrosarcoma (FS) are tumors of Swiss mouse origin and have been described earlier [21, 22]. Tumor cell lines such as FS, LSA and EL4 were cultured in RPMI-1640 medium and tumor cell lines such as A549, INT407, MCF7 and NIH 3T3 were cultured in DMEM medium. Both RPMI1640 and DMEM were supplemented with sodium bicarbonate $(2 \mathrm{~g} / \mathrm{L}), 2$-mercaptoethanol $\left(5 \times 10^{5} \mathrm{M}\right), 10 \%$ heat inactivated fetal calf serum (FCS), penicillin $(100 \mathrm{U} / \mathrm{ml})$ and streptomycin $(100 \mu \mathrm{g} / \mathrm{ml})$.

\section{Drugs used for Anticancer Activity}

Arg free RPMI-1640, PBS and DMEM medium was used to prepare various Arg solutions for studies. In case of Arg free RPMI-1640 and PBS known amount Arg powder was added to make desired concentration. In case of DMEM where basal concentration of L-Arg was $0.48 \mathrm{mM}$, was considered to make desired concentration. In case of D-Arg preparation in RPMI 1640, PBS and DMEM medium known amount of D-Arg powder was added to make desired concentration. DMEM containing $0.48 \mathrm{mM}$ of L-Arg and RPMI 1640 containing $1.1 \mathrm{mM}$ of L-Arg was used for $24 \mathrm{~h}$ culture. L-Arg free base, D-Arg free base, agmatine-sulphate salt and L-Lysine free base (L-Lys), N $\omega$-Nitro-L-arginine methyl ester hydrochloride (L-NAME), N $\omega$-Nitro-Darginine methyl ester hydrochloride (D-NAME) (Sigma, St. Louis, USA) were dissolved either in medium, $\mathrm{pH} 7.4$ (M) or PBS, pH $7.4(\mathrm{P})$. The cytotoxicity was assessed by trypan blue dye exclusion test, ${ }^{51}$ Chromium release assay (CRA), ${ }^{3} \mathrm{H}$-thymidine based proliferation assay, confocal microscopy and in vivo tumor inhibition assay.

\section{Photomicrograph of Tumor Cells}

Tumor cells $\left(1 \mathrm{X} 10^{6 /} / \mathrm{ml}\right)$ of different types (MCF7, A549, INT407, LSA and EL4) were incubated with L-Arg in PBS (L-Arg-P) or L-Arg in medium (L-Arg-M) in a test tube for $1 \mathrm{~h}$ at $37{ }^{\circ} \mathrm{C}$ in a humidified $\mathrm{CO}_{2}$ incubator. LSA cells $\left(1 \mathrm{X} 10^{6 /} / \mathrm{ml}\right)$ were incubated with L-Arg or D-Arg in PBS either in the presence of NOS inhibitor L-NAME or its enantiomer D-NAME in a test tube for $1 \mathrm{~h}$ at $37{ }^{\circ} \mathrm{C}$ in a humidified $\mathrm{CO}_{2}$ incubator. Later, the cells were centrifuged for $5 \mathrm{~min}$ at $3000 \mathrm{rpm}$ and then resuspended in medium containing $10 \%$ FCS. The contents in the test tube were transferred to 24 well plate. Photomicrograph were recorded using Nikon camera attached to Nikon Phase Contrast microscope at $20 \mathrm{X}$ magnification after $24 \mathrm{~h}$ (ELWD 0.2, Japan).

\section{Tumor Cell Membrane Damage Studies Using Confocal Microscopy}

After treatment with various concentration of L-Arg-P, LSA cells were harvested and washed with PBS. PI stain (Sigma, Cat no P4170) was added to tumor cell suspension $\left(1 \mathrm{X} 10^{6}\right.$ cells $\left./ \mathrm{ml}\right)$ to a final concentration of $1 \mu \mathrm{g} / \mathrm{ml}$ and after 5 minutes Hoechst 33342 DNA (Sigma, Cat no. B2261) stain was added to a final concentration of $5 \mu \mathrm{g} / \mathrm{ml}$. After mixing briefly, the stained cells were observed after 5 minutes of incubation with confocal microscopy (LSM 510META, Zeiss, Germany). To study the early apoptotic process $1 \mathrm{ml}$ of L-Arg-P treated tumor cell suspension $\left(1 \times 10^{6}\right.$ cells $\left./ \mathrm{ml}\right)$ was stained with $5 \mu 1$ annexin-V FITC conjugate (Sigma, Cat no. A9210) and $10 \mu \mathrm{l}$ of PI stain, incubated for $10 \mathrm{~min}$ in dark and observed under confocal microscope. For video, tumor cells $\left(1 \times 10^{6}\right.$ cells/ ml) were seeded in P-30 Petriplates (BD Falcon) and allowed to form monolayer for $24 \mathrm{hr}$ at $37^{\circ} \mathrm{C}$ in a humidified $\mathrm{CO}_{2}$ incubator. The plate was treated with $50 \mathrm{mM}$ of Arg either in PBS or medium. The plate was kept for $1 \mathrm{~h}$ on the confocal microscope stage for live imaging.

\section{Caspase Activity}

Caspase 3 activity was performed using Caspase 3 Colorimetric Assay kit (Sigma, St. Louis USA). 1 X $10^{6}$ cells with various concentration of Arg in PBS and medium was incubated for 4 and $24 \mathrm{~h}$ and further analysis was carried out following manufacturer's protocol.

\section{NOx Assay}

LSA cells $\left(1 \mathrm{X} 10^{6 /} / \mathrm{ml}\right)$ were incubated with either L-Arg$\mathrm{P}$ or D-Arg-P in 24 well plate for $1 \mathrm{~h}$ at $37{ }^{\circ} \mathrm{C}$ in a humidified $\mathrm{CO}_{2}$ incubator. Later, the cells were centrifuged for $5 \mathrm{~min}$ at $3000 \mathrm{rpm}$ and the supernatant was assayed for NOx (nitrite + nitrate) levels using the commercial nitric oxide assay kit (Calbiochem, Germany) as per the manufacturer's protocol.

\section{${ }^{51}$ Chromium Release Assay (CRA)}

The method is essentially as reported earlier [23]. CRA measures the target cell membrane damage and death which relates to the loss of plasma membrane integrity leading to the leakage of cellular components. CRA was performed with tumor cell line LSA. Briefly, tumor cells $\left(18 \times 10^{6} / 320\right.$ $\mu$ l) were labeled with $180 \mu 1 \mathrm{Na}_{2}{ }^{51} \mathrm{CrO} 4(180 \mu \mathrm{Ci}$; Specific activity of $4.3 \mathrm{mCi} / \mathrm{mmole}$ of ${ }^{51} \mathrm{Cr}$ in the form of $\mathrm{Na}_{2} \mathrm{CrO}_{4}$ in isotonic saline; Board of Radiation \& Isotope Technology, Department of Atomic Energy, Mumbai, India) by incubating at $37^{\circ} \mathrm{C}$. for $1 \mathrm{~h}$. The ${ }^{51} \mathrm{Cr}$ labeled cells were washed with excess of medium to remove free $\mathrm{Na}_{2}{ }^{51} \mathrm{CrO}_{4}$ and finally suspended either in PBS or medium. Labeled cells $\left(10^{5} / 100\right.$ $\mu \mathrm{l})$ in 96 well plate were treated with different concentration 
of L-Arg or D-Arg either in PBS or medium for $1 \mathrm{~h}$ at $37^{\circ} \mathrm{C}$ in hexareplicates. After incubation the plates were centrifuged and $50 \mu 1$ supernatants were added to Dioxane-based scintillation cocktail (10 g PPO, $250 \mathrm{mg}$ POPOP, $100 \mathrm{gm}$ naphthalene dissolved in 1 litre Dioxane). The radioactivity was measured in LS Analyzer (TriCarb 2900 TR Packard, A Packard Bioscience Company) using an energy window of 0$2000 \mathrm{KeV}$. Radioactivity was expressed as counts per minute (cpm) which was used for statistical analysis. Appropriate low controls (LC), which indicates the spontaneous release in the supernatant in the absence of Arg in the respective group and high controls $(\mathrm{HC})$, which indicate the radioactive release in the supernatant in 10\% SDS (Sodium dodecyl sulphate) treated cells were included. Percent specific release of ${ }^{51} \mathrm{Cr}$ was calculated by the following formula:

$\%$ Specific ${ }^{51} \mathrm{Cr}$ release $=[($ Radioactivity in Arg-treated group - LC) $\div(\mathrm{HC}-\mathrm{LC})] \times 100$

\section{${ }^{3}$ H-Thymidine-Based Cell Proliferation Assay}

Tumor cell proliferation was measured according to the method described earlier [21]. ${ }^{3} \mathrm{H}$-Thymidine-based cell proliferation assay was performed with tumor cell lines (FS, LSA, MCF7, A549 and NIH 3T3). Briefly, tumor cells $\left(10^{5} / 100 \mu \mathrm{l}\right)$ in 96 well plate were treated with different concentrations of L-Arg or D-Arg either in PBS or medium. After $1 \mathrm{~h}$ incubation at $37^{\circ} \mathrm{C}, 100 \mu \mathrm{l}$ of medium containing $20 \%$ FCS was added to all the wells. After $24 \mathrm{~h}$, the cells were pulsed with ${ }^{3} \mathrm{H}$-thymidine $(1 \mu \mathrm{Ci} /$ well; Specific activity: $6.5 \mathrm{Ci} / \mathrm{mmole}$, Board of Radiation \& Isotope Technology, Department of Atomic Energy, Mumbai, India). The cultures were harvested after $16 \mathrm{~h}$ on glass fiber filters using a Multimash-2000 harvester (Dynatech Laboratories Inc., USA). The incorporated radioactivity was counted in a toluene-based scintillation fluid using LS Analyzer (TriCarb 2900 TR Packard, A Packard Bioscience Company). Radioactivity was expressed as cpm. Cpm values were used for statistical analysis. Controls indicate thymidine incorporation in cells treated in the absence of Arg.

\section{Hemolysis Assay}

Fresh human blood were collected by finger puncture, from a healthy donor (who was fasting and not submitted to any drug treatment), working in our laboratory with informed consent. The blood sample was diluted 50 times with isotonic PBS, pH 7.4 and used in the assay [24]. Blood collected from Swiss mice by tail vein puncture was processed similarly and used in the assay. We plotted the percent red blood cell (RBC) hemolysis as a function of osmolarity and calculated the mean corpuscular fragility (MCF), which represents osmolarity at which 50 percent hemolysis is observed.

\section{Concanavalin A (Con-A)-Induced Mitogenesis}

Mitogenesis was done according to the method described earlier [21]. Briefly, splenic lymphocytes were obtained by hypotonic treatment using Tris-Ammonium chloride $(0.83 \%$, $\mathrm{pH}$ 7.2). One million splenocytes/ $\mathrm{ml}$ were incubated with various concentrations of L-Arg either in PBS or RPMI 1640 medium for $1 \mathrm{~h}$ at $37^{\circ} \mathrm{C}$, centrifuged and were resuspended in RPMI 1640 medium at a density $10^{6} / \mathrm{ml}$ containing $10 \%$ FCS. The cells $\left(2 \times 10^{5} / 200 \mu \mathrm{l}\right)$ in 96 well plate were stimu- lated with $\mathrm{T}$ cell mitogen Con-A $(10 \mu \mathrm{g} / \mathrm{ml})$ for $72 \mathrm{~h}$ and were pulsed with ${ }^{3} \mathrm{H}$ thymidine $(1 \mu \mathrm{Ci} /$ well). The splenocytes were further cultured for 16 hours and were harvested on glass fiber filters using a Multimash-2000 harvester (Dynatech Laboratories Inc., USA). The incorporated radioactivity was counted in a toluene-based scintillation fluid using LS Analyzer (TriCarb 2900 TR Packard, A Packard Bioscience Company). Radioactivity was expressed as cpm which was used for statistical analysis.

\section{In vivo Therapy of Murine Tumors}

Single cell suspension of the FS cells were prepared as reported earlier and injected subcutaneously at ventro-lateral position of mice on day 0 [22]. FS therapy was initiated on day 7, post tumor transplantation when the average tumor diameter was $4.5-5.6 \mathrm{~mm}$. The treatment was continued on day 8, 9 and 10th day of tumor transplantation. Various drug delivery schedules as mentioned in results were injected intratumorally $0.02 \mathrm{ml} /$ gram body wt. into the centre of tumor base, once a day. Injection was performed slowly over 30 seconds without moving the needle, to ensure uniform diffusion of the solution. For these injections, no leakage of solution around the needle or out of the tumor was observed. Single cell suspension of the LSA tumor was prepared as reported earlier and injected intraperitoneally (i.p.) on day 0 [21]. In case of LSA therapy a bolus injection of various drug delivery schedules as mentioned in results was given i.p., $0.03 \mathrm{ml} / \mathrm{gram}$ body wt on day $3,5,7$ and 9 of tumor transplantation, once a day. Sham group indicates tumor bearing mice which were untreated and handled similar to experimental group. Tumor diameter was monitored in the case of solid FS tumor and survivals were monitored in the case of FS and ascitic LSA. When tumor diameter reached $25 \mathrm{~mm}$ in FS bearing mice, animals were sacrificed. In case of LSA when the mice showed severe distress due to distended peritoneal cavity because of ascites formation, they were sacrificed. The day of sacrifice was considered for monitoring the survival period. The mice which were tumor free on day 30 were monitored for the presence of visible tumors. Tumor free mice surviving on day 120 of tumor transplantation were considered cured of tumor.

\section{Statistical Analyses}

Statistical analyses were performed using ANOVA followed by post-hoc analysis by Schiffe's test. Fractions of tumor free mice were analyzed using Fishers exact probability test. MCF data for RBC hemolysis were analyzed by using probit analysis SPSS version 12.0 windows. Difference of MCF values at various Arg concentrations from control was compared by using ANOVA followed by posthoc analysis by Tukey's HSD multiple comparison test (SPSS 12.0 for windows). We rejected the null hypothesis at a P value of 0.05 . The IC50 and IC90 values were calculated using Origin 6.0 software.

\section{RESULTS}

\section{Arg in PBS Causes Clumping of Tumor Cells}

Mouse tumor cell lines such as LSA and EL4 and human tumor cell lines such as MCF7, A549 and INT407 formed large slimy aggregates or clump after the treatment with L- 

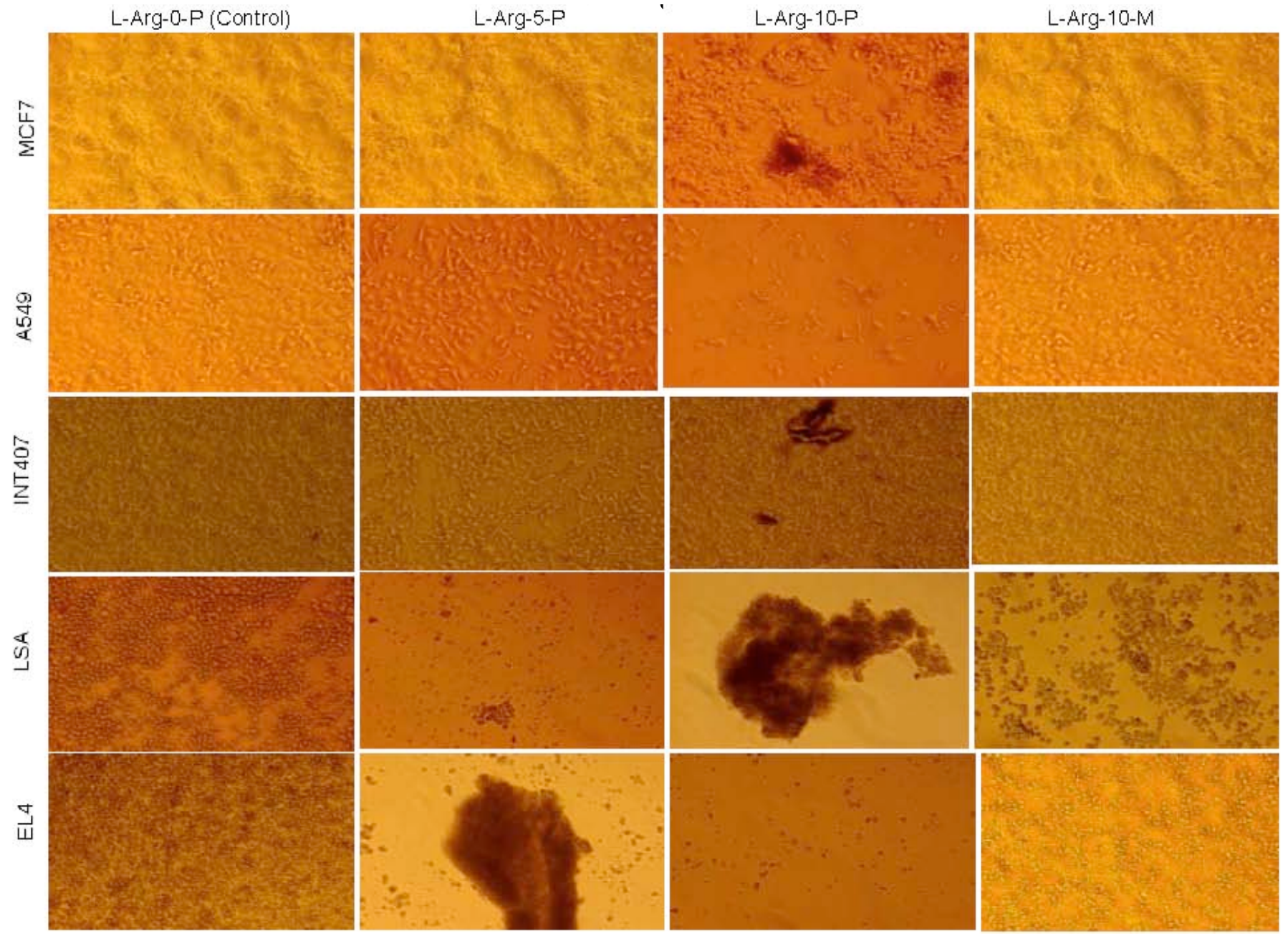

Fig. (1). Arg in PBS causes clumping of tumor cells. Representative photomicrographs (20X magnification) of different tumor cells (MCF7, A549, INT407, LSA, and EL4) after incubation with L-Arg-P or L-Arg-M at $37^{\circ} \mathrm{C}$ for $1 \mathrm{~h}$, followed by centrifugation and $24 \mathrm{~h}$ of culture. Label indicates Drug, Dose of the drug in $\mathrm{mM}$ and Delivery vehicle (P or M) in the order separated by a hyphen.

Arg-P and centrifuged (Fig. 1). The results also indicate heavy cell loss in LSA, EL4, MCF7 and A549 tumor cells treated with Arg-P, possibly indicating the cell lysis. Tumor cells treated with D-Arg-P treated similarly caused clumping (Fig. S1). However, treatment of these tumor cells, with 10 $\mathrm{mM}$ L-Arg-M did not cause either cell aggregation or cell loss of the above tumor cell lines (Fig. 1). L-Lys, a cationic amino acid and agmatine-sulphate, the decarboxylated metabolic product of Arg containing guanidine group did not cause clumping of the tumor cells when delivered in PBS at a concentration of $10 \mathrm{mM}$ (Fig. S1). The results indicate the ability of Arg to cause tumor cell damage when presented in PBS and not in medium.

\section{Arg in PBS Causes Tumor Cell Membrane Damage}

Arg at $10 \mathrm{mM}$ delivered in PBS and not in medium killed more than $80 \%$ of LSA cells by 45 minutes, and Arg at 50 $\mathrm{mM}$ delivered in PBS and not in medium killed more than 95\% of LSA cells by 15 minutes, as assessed by trypan blue staining (data not shown). However, L-Lys and agmatinesulphate at $10 \mathrm{mM}$ did not cause membrane damage as assessed by trypan blue exclusion test, even after $1 \mathrm{~h}$ of incubation (Table 1). Studies were done in detail to see the ability of various concentrations of L-Arg to cause membrane alterations in LSA tumor cells, by observing the confocal images of Hoechst and PI stained tumor cells. The

Table 1. Arg in PBS Causes LSA Cell Membrane Damage

\begin{tabular}{|c|c|}
\hline Treatment group & Percentage of viable cells \\
\hline \hline L-Arg-10--P & 20 \\
\hline L-Arg-10-M & 95 \\
\hline L-Arg-50-P & 5 \\
\hline L-Arg-50-M & 94 \\
\hline L-Lys-10-P & 94 \\
\hline L-Lys-10-M & 98 \\
\hline Agmatine sulphate-10-P & 96 \\
\hline Agmatine sulphate-10-M & 97 \\
\hline
\end{tabular}

The membrane integrity was assessed by trypan blue dye exclusion test with LSA after $1 \mathrm{~h}$ treatment. Treatment group indicates Drug, Dose of drug in $\mathrm{mM}$ and Delivery vehicle $(\mathrm{P}$ or $\mathrm{M})$ in the order separated by a hyphen. 
LSA cells treated with only PBS and L-Arg-P at $5 \mathrm{mM}$ showed majority of blue stained cells indicating the intact cell membrane (Fig. 2a and 2b) whereas LSA tumor cells treated with L-Arg-P at $10 \mathrm{mM}$ showed intense red stain with PI, indicating severe damage of tumor cell membrane and formation of clump (Fig. 2c). However, treatment of LSA cells, with $10 \mathrm{mM}$ L-Arg-M did not lead to membrane damage as no remarkable PI staining was seen in tumor cells (Fig. 2d). There was absence of annexin-V FITC stained cells and PI stained cells in control (Fig. 2e). In case of LArg-P at $10 \mathrm{mM}$ intense PI staining and absence of annexin$\mathrm{V}$ FITC stained cells indicated that the death was contributed due to extensive L-Arg-P induced necrosis of the tumor cells

a

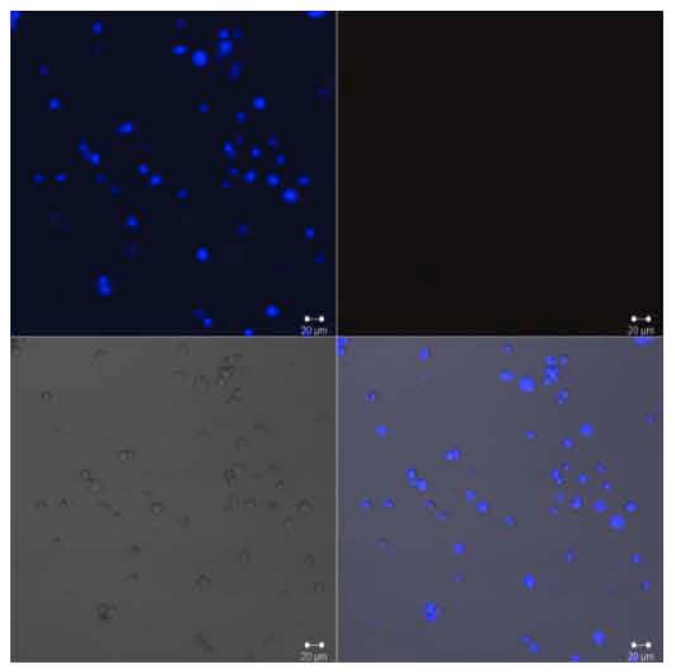

L-Arg-0-P (Control)

C

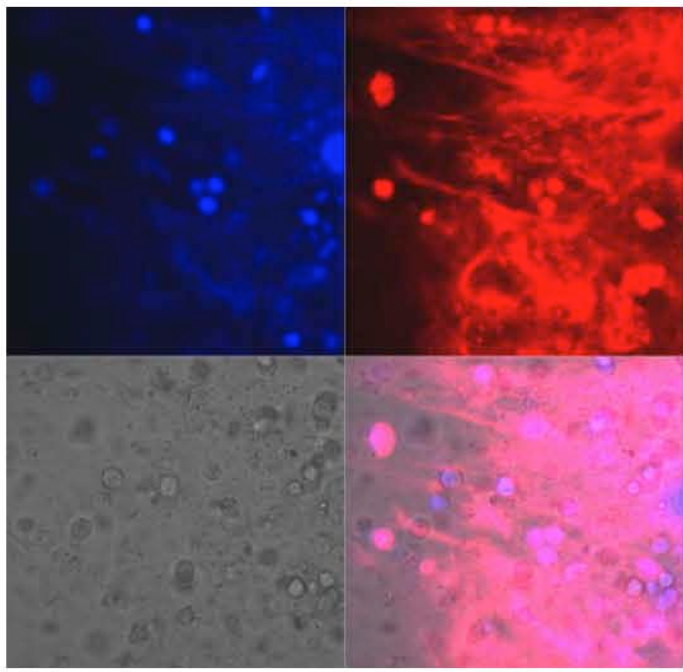

L-Arg-10-P and not due to apoptosis (Fig. 2f). Further, there was no detectable levels of caspase 3 activity in LSA cells treated with Arg up to $300 \mathrm{mM}$ either in PBS or medium (data not shown) suggesting the exclusion of the apoptotic pathway as the primary event in the observed anticancer effect of Arg. Tumor cells incubated with L-Arg-P at $10 \mathrm{mM}$ for $1 \mathrm{~h}$ caused aggregation of tumor cells and lead to the formation of mat-like structure (Fig. 2g). Live confocal images of the tumor cells indicated a significant alteration in the tumor cell morphology, at $15 \mathrm{~min}$ of incubation with L-Arg-P at $50 \mathrm{mM}$ and not with L- Arg-M at $50 \mathrm{mM}$ (Movie S1, Fig. S2).

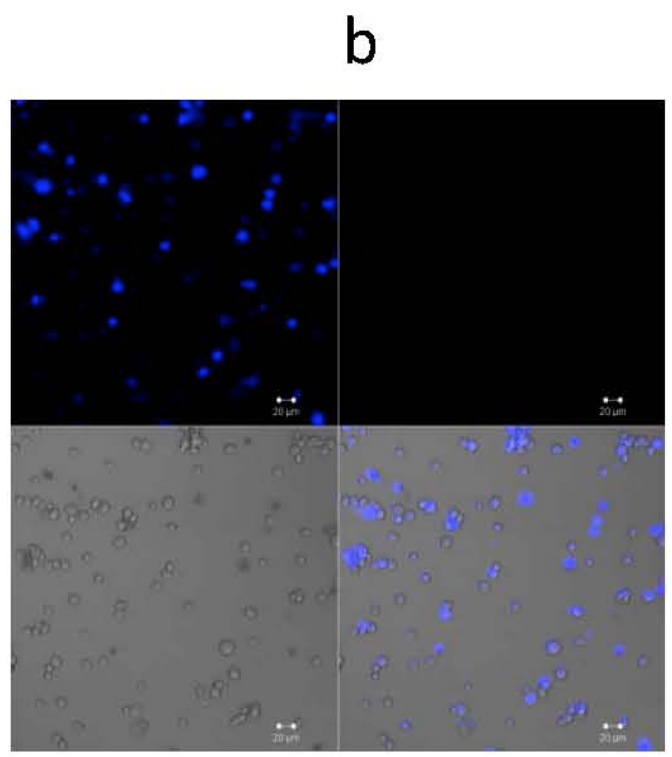

L-Arg-5-P

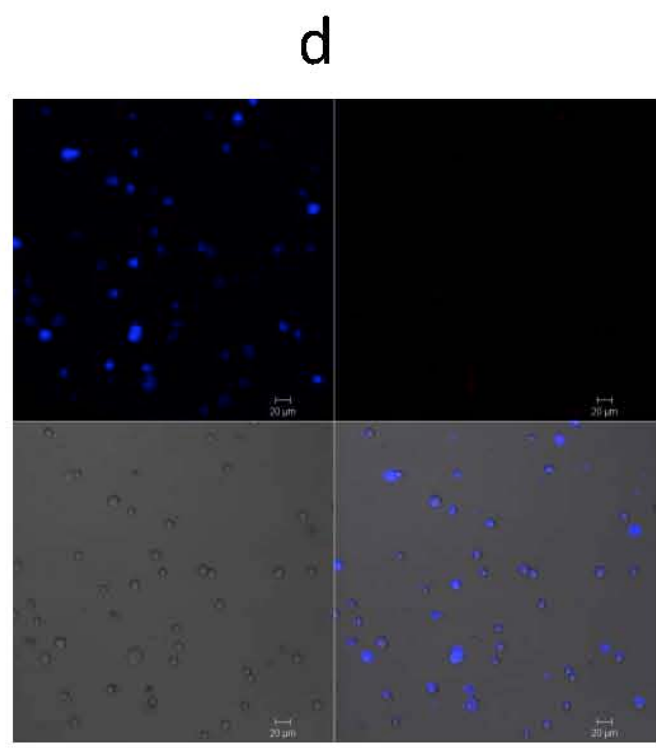

L-Arg-10-M 
e

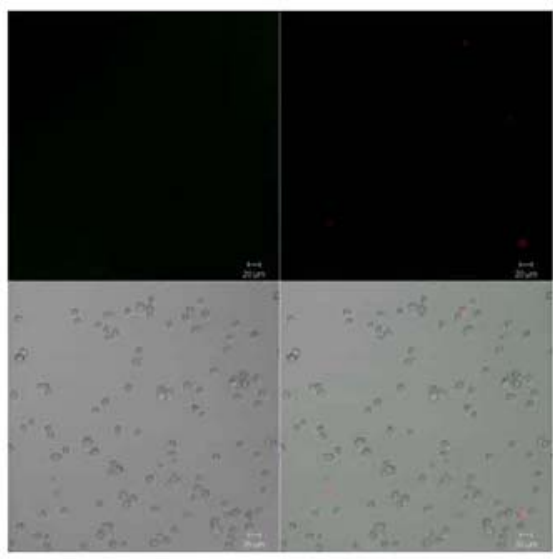

L-Arg-0-P (Control)

L-Arg-10-P g

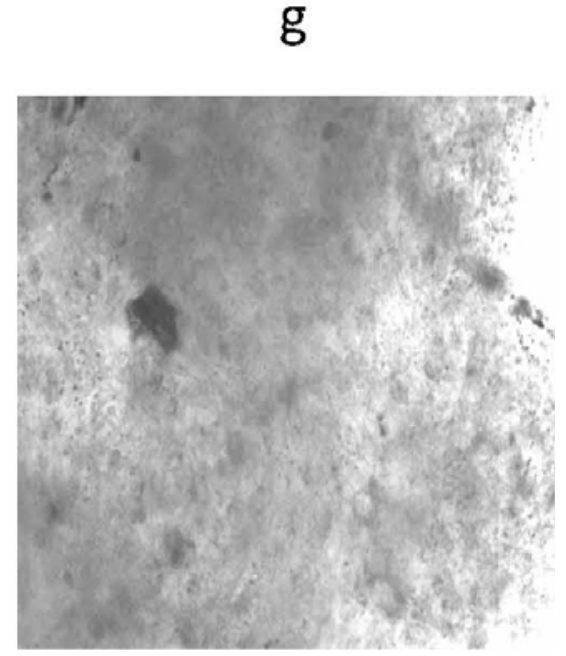

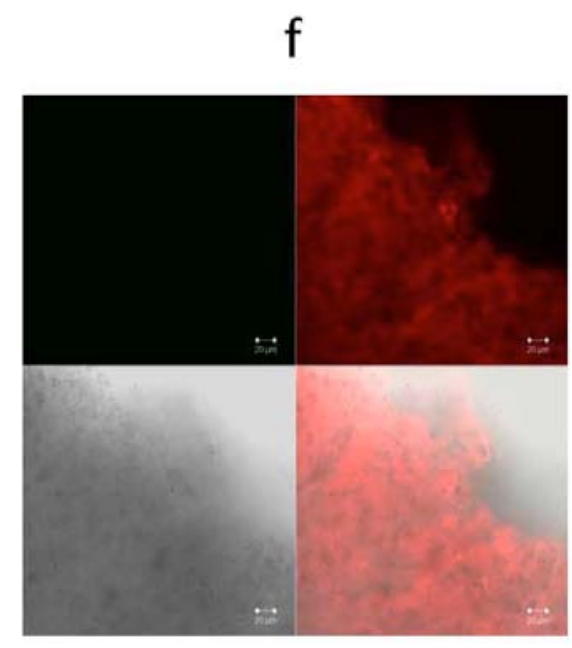

L-Arg-10-P

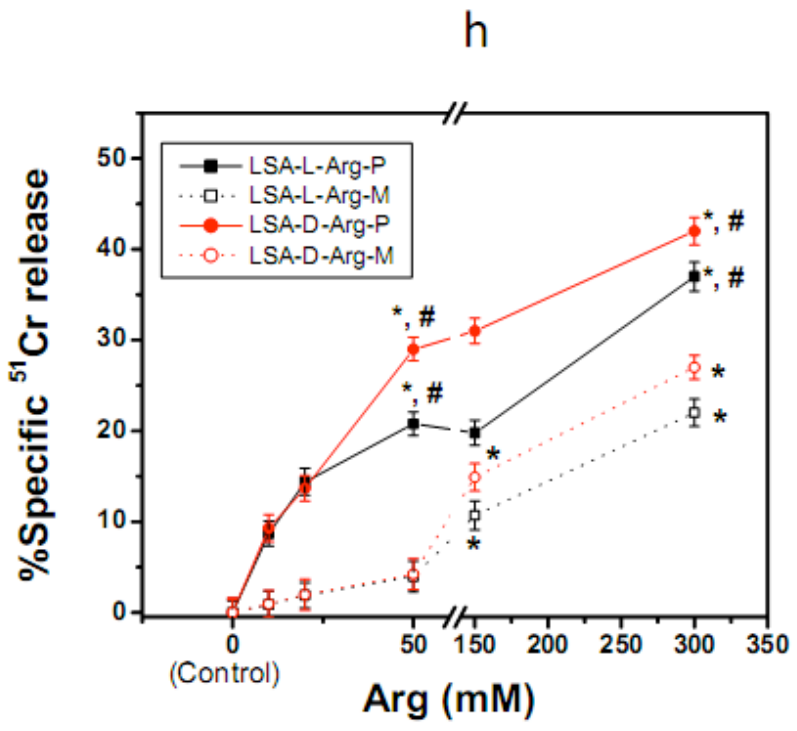

Fig. (2). Arg in PBS causes tumor cell membrane damage. Confocal photomicrograph of LSA cells treated with L-Arg-P to observe membrane changes at 40X magnification. a. Cells treated with PBS with no Arg supplementation (control) show blue staining by Hoechst indicating live cells. b. Cells treated with $5 \mathrm{mM} \mathrm{L-Arg}$ in PBS show blue staining by Hoechst indicating live cells. c. Cells treated with $10 \mathrm{mM}$ L-Arg in PBS show intense red staining with PI indicating necrotic cells. d. Cells treated with 10mM L-Arg in medium show blue staining by Hoechst indicating live cells. e. \& f. Cells stained with the annexin V-FITC and PI. e. Cell treated with PBS with no Arg supplementation (control) neither showed annexin V-FITC nor PI stain indicating live cells. f. Cells treated with 10mM L-Arg in PBS showed absence of annexin V-FITC and intense red PI staining of the clump as seen in bright field image indicating necrosis and absence of apoptosis. In each panel top left: Hoechst (blue)/ Annexin V-FITC (green); top right: PI staining; bottom left: bright field image; bottom right: overlay images of all three above mentioned panels. g. Bright field image of tumor cells forming mat-like structure when treated with $\mathrm{L}$-Arg-P at $10 \mathrm{mM}$ for $1 \mathrm{~h}$. Label indicates Drug, Dose of the drug in $\mathrm{mM}$ and Delivery vehicle $(\mathrm{P})$ in the order separated by a hyphen. h. Arg in PBS causes membrane disruption of tumor cells. Effect of L-Arg-P, D-Arg-P (solid lines) and L-Arg-M, D-Arg-M (dotted lines) on LSA tumor cells as evaluated by CRA. Each point is the mean \pm SEM of six replicates of a representative experiment. Three such independent experiments were performed. Key indicates Cell line, Drug and Delivery vehicle (P or M) in the order separated by a hyphen. To give details of the dose response of tumor cells at lower concentrations of Arg a break is introduced in the $\mathrm{X}$-axis between 50 and $150 \mathrm{mM} .{ }^{*} \mathrm{P}<0.05$ from respective control group; ${ }^{*} \mathrm{P}<$ 0.05 respective medium group.

\section{NO does not Contribute to the Anticancer Effect of Arg}

Nitric oxide synthase (NOS) inhibitor L-NAME, a nonselective inhibitor of NOS and its enantiomer D-NAME, inhibit the clumping of LSA tumor cells induced by either LArg-P or D-Arg-P (Fig. S3). The results suggest that both L-
NAME and D-NAME prevented the anticancer effect of Arg through its chemical structure. To demonstrate the involvement of NO, NOx (nitrite+ nitrate) levels in the supernatant of LSA tumor cells treated with $10 \mathrm{mM}$ of Arg in PBS environment were assayed. The results indicate that 
there is no increased production of $\mathrm{NO}$, in Arg-P group compared to the control group, which demonstrates that NO is not contributing to the anticancer effect of Arg (Fig. S4).

\section{Arg in PBS Causes Membrane Disruption of Tumor Cells}

Experiments were done with CRA to monitor the tumor cell membrane damage induced by Arg treatment for $1 \mathrm{~h}$ in PBS or medium environment on LSA. Our data on CRA indicated that treatment of tumor cells with both the enantiomers of Arg-P caused dose dependent membrane damage up to $300 \mathrm{mM}$ of Arg (Fig. 2h). Treatment with Arg$M$ did not show significant membrane damage in LSA tumor cell below 50mM. However, treatment with Arg-M at 150 $\mathrm{mM}$ and beyond showed significant membrane damage in tumor cell lines. In conclusion, Arg induced necrotic death of tumor cells in a dose dependent manner. These results suggest the importance of Arg concentration and the delivery environment in Arg-induced tumor cell killing.

a

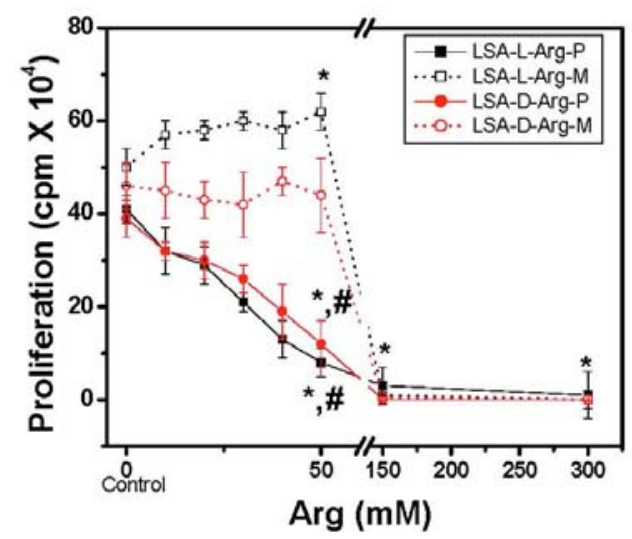

C

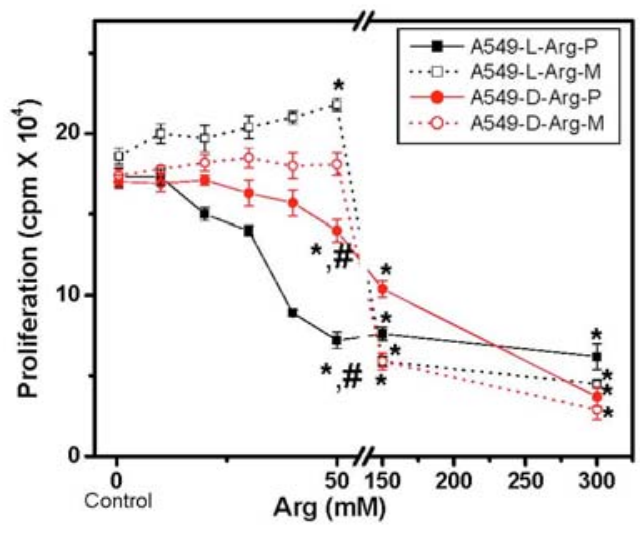

\section{Arg in PBS becomes Effective Anticancer Molecule}

Since it is the ability of the remaining tumor cells to proliferate in order to determine whether a tumor can grow, we designed the experiments to find out the proliferative ability of the tumor cells remaining after Arg treatment for 1 $\mathrm{h}$, using ${ }^{3} \mathrm{H}$-thymidine based proliferation assay. Incubation period of $1 \mathrm{~h}$ was selected based on confocal studies on tumor cell membrane damage. This will establish the ability of Arg to act as an anticancer molecule depending on the concentration and delivery environment. After $1 \mathrm{~h}$ incubation with Arg tumor cells were cultured for $24 \mathrm{~h}$ in medium containing FCS. We used Arg concentration up to $300 \mathrm{mM}$ since these higher pharmacological concentrations were used to treat murine tumors in vivo. Both L-Arg and D-Arg at 50 $\mathrm{mM}$ inhibited growth of all the tumor cell lines when delivered in PBS and not in medium (Fig. 3a-d). Tumor cells treated with L-Arg-M up to $50 \mathrm{mM}$ indicated significantly increased tumor cell proliferation in all the cell lines except MCF7. However, tumor cells treated with D-Arg-M up to 50

b

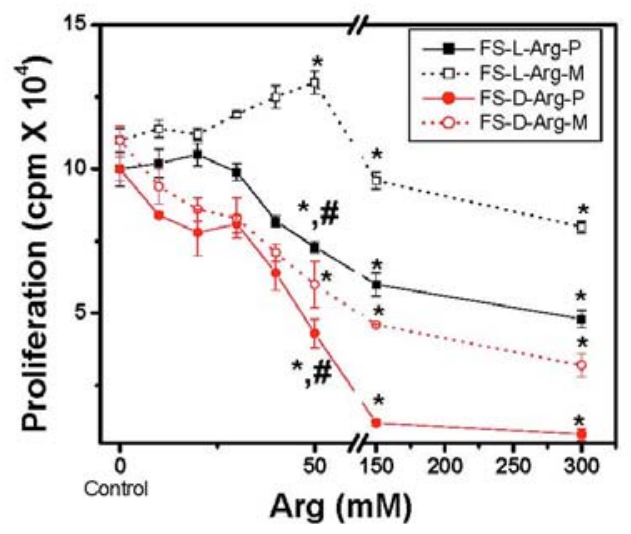

d

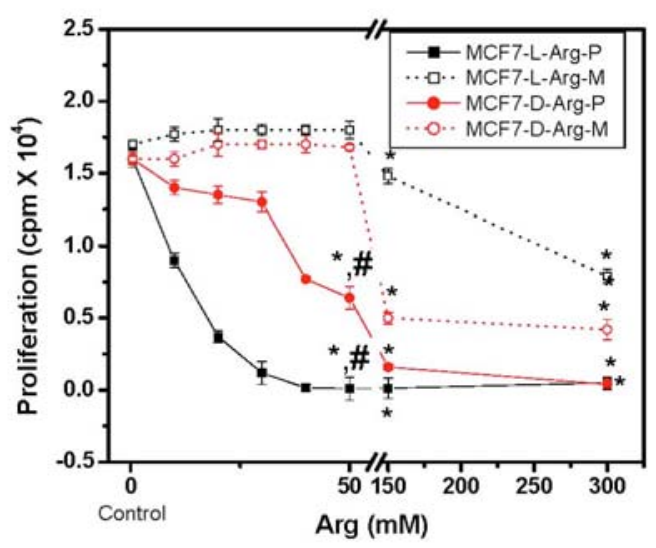

Fig. (3). Arg in PBS inhibits tumor cell proliferation. a. Effect of L-Arg-P, D-Arg-P, L-Arg-M and D-Arg-M on the proliferation of LSA tumor cells. b. Effect of L-Arg-P, D-Arg-P, L-Arg-M and D-Arg-M on the proliferation of FS tumor cells. c. Effect of L-Arg-P, D-Arg-P, LArg-M and D-Arg-M on the proliferation of A549 tumor cells. d. Effect of L-Arg-P, D-Arg-P, L-Arg-M and D-Arg-M on the proliferation of MCF7 tumor cells. L-Arg-P \& D-Arg-P are depicted by solid lines and L-Arg-M \& D-Arg-M by dotted lines. Each point is the mean \pm SEM of six replicates of a representative experiment. Three such independent experiments were performed. Key indicates Cell line, Drug and Delivery vehicle (P or $\mathrm{M})$ in the order separated by a hyphen. To give details of the dose response of tumor cells at lower concentrations of Arg a break is introduced in the $\mathrm{X}$-axis between 50 and $150 \mathrm{mM}$. ${ }^{*} \mathrm{P}<0.05$ from respective control group; ${ }^{\#} \mathrm{P}<0.05$ respective medium group. 
$\mathrm{mM}$ did not increase the tumor cell proliferation of all the above tumor cell lines. Arg at $150 \mathrm{mM}$ and above irrespective of chirality and incubation vehicle became an effective anticancer molecule against all the four cell lines tested. The IC50 and IC90 values of Arg in various delivery vehicles are presented in Table 3 . The results indicate the relative sensitivities of various tumor cell lines to Arg. MCF7 seem to be the most sensitive to Arg-P. The result also suggests the dependence on chirality of Arg and delivery vehicle in preventing the tumor cell proliferation. In conclusion, the results indicated an increased anticancer activity of Arg when delivered in PBS. In medium environment Arg becomes an anticancer molecule at higher concentration.

\section{Effects of Arg on Normal Cells}

Drug induced cytolytic activities against normal mammalian cells and erythrocytes have a large clinical relevance. Since systemic concentration of Arg achieved in the human body is much below $20 \mathrm{mM}$ and Arg in PBS environment is a better anticancer molecule, we tested the effect of treatment with Arg in PBS environment up to $50 \mathrm{mM}$ on normal

a

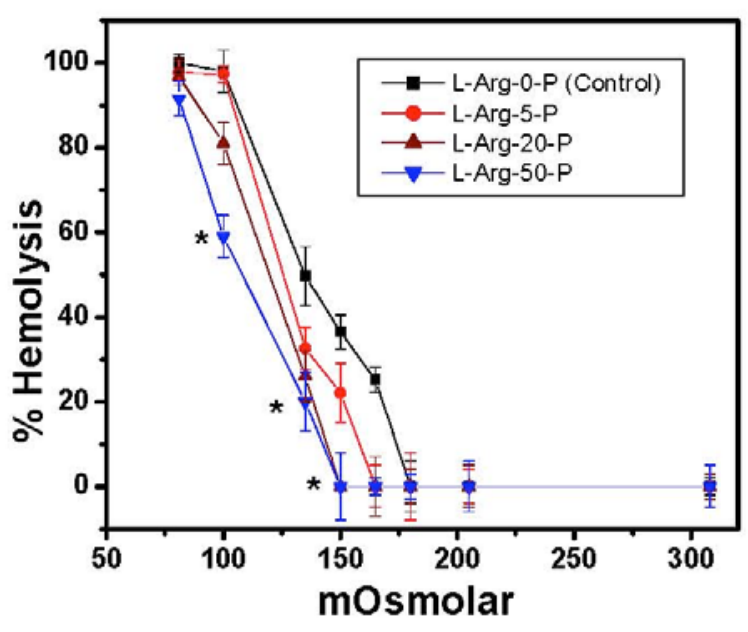

C

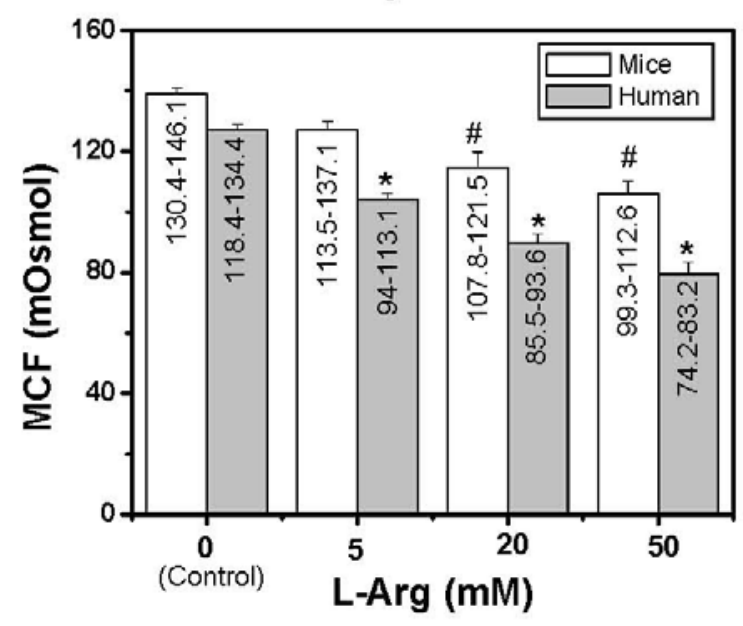

cells like human and murine erythrocytes, murine splenic lymphocytes and NIH $3 \mathrm{~T} 3$ cell lines. We observed that treatment of both murine and human erythrocytes with LArg-P up to $50 \mathrm{mM}$ was non toxic as revealed by osmotic fragility test (Fig. 4a-c). On the contrary, L-Arg-P treatment decreased the osmotic fragility of both murine and human erythrocytes as reflected in the shift of mean corpuscular fragility (MCF) towards lower osmolarity, suggesting that LArg stabilizes the erythrocyte membrane and prevents hypotonic induced hemolysis (Fig. 4c). Treatment of splenocytes with L-Arg-M for $1 \mathrm{~h}$, significantly enhanced the ConA induced proliferation of splenocytes (Fig. 4d), when compared to treatment with L-Arg-P. Further, treatment with L-Arg-P at $50 \mathrm{mM}$ for $1 \mathrm{~h}$ significantly enhanced the Con A induced proliferation of splenocytes (Fig. 4d), when compared to the control. Normal Swiss mouse lymphocytes become the perfect control for the LSA cells, as LSA tumor is derived in the syngeneic Swiss mice [21]. Further, treatment of NIH 3T3 fibroblast with either L-Arg-P or LArg-M did not inhibit the cell proliferation (Fig. 4e). NIH 3T3 cell line is a mouse fibroblast cell line of Swiss mouse origin and used as the normal counter part for the fibrosarcoma tumor cell line studies [25].

b

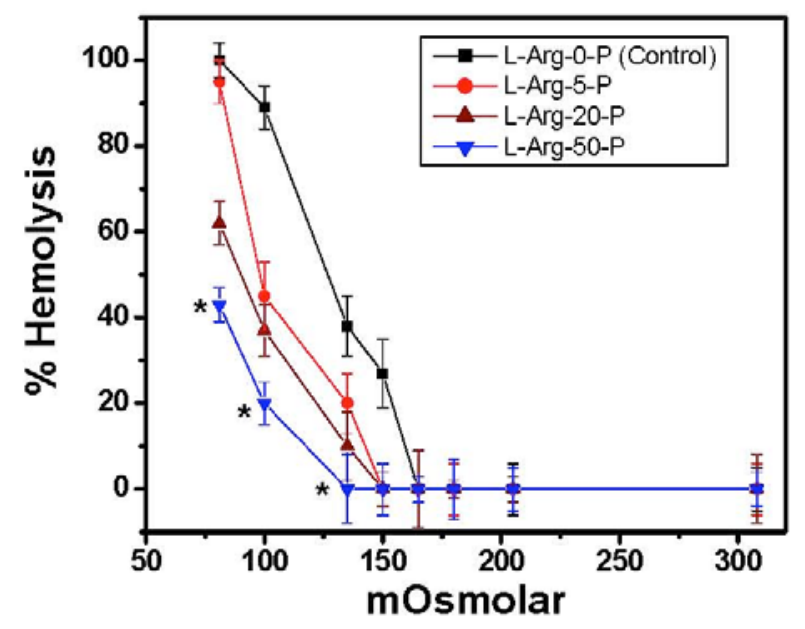

d

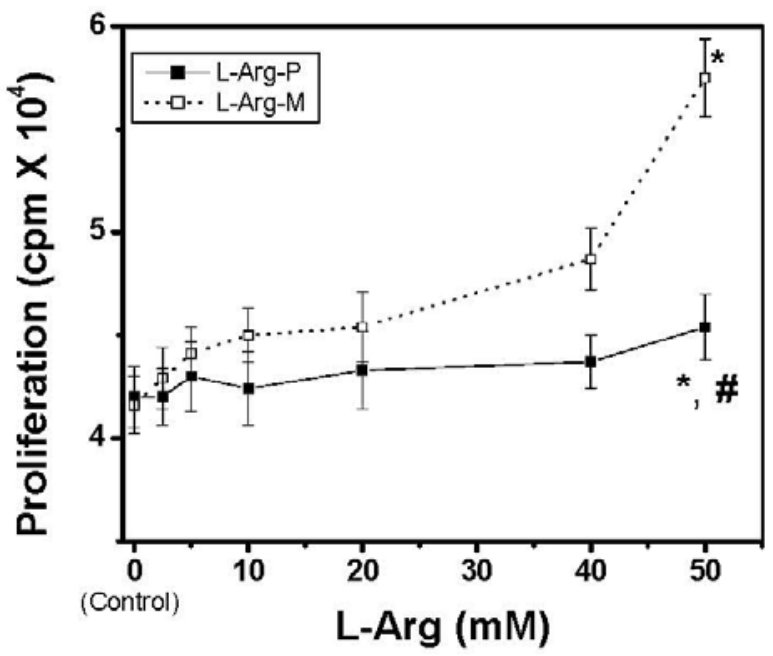


(Fig. 4) Contd.....

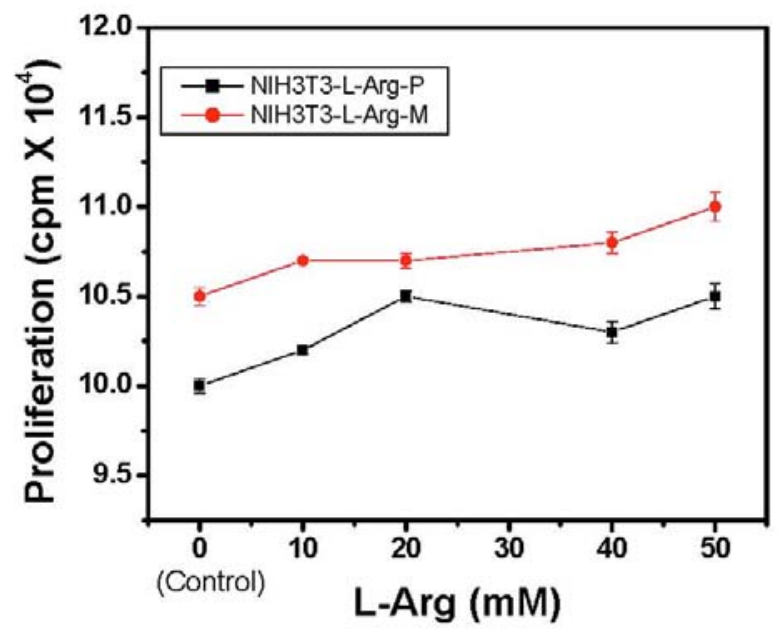

Fig. (4). Effects of Arg on normal cells. a. \& b. Effect of L-Arg-P on a murine and b human erythrocyte hemolysis. Each point is the mean \pm SEM of four replicates of a representative experiment. Three such independent experiments were performed. Key indicates Drug, Dose of the drug in $\mathrm{mM}$ and Delivery vehicle $(\mathrm{P})$ in the order separated by a hyphen. ${ }^{*} \mathrm{P}<0.05$ from respective control group. c. Mean corpuscular fragility (MCF) of murine (open bar) and human erythrocytes (shaded bar). The $95 \%$ confidence interval as evaluated by probit analysis for each group is indicated inside each bar. ${ }^{*} \mathrm{P}<0.05$ from respective control group in human and ${ }^{\#} \mathrm{P}<0.05$ from respective control group in mice. d. Effect of L-Arg-P (solid lines) and L-Arg-M (dotted lines) on Con-A induced mitogenesis of splenic lymphocytes. Each point is the mean \pm SEM of eight replicates of a representative experiment. Three such independent experiments were performed. Key indicates Drug and Delivery vehicle $(\mathrm{P}$ or $\mathrm{M})$ in the order separated by a hyphen. ${ }^{*} \mathrm{P}<0.05$ from respective control group and ${ }^{\#} \mathrm{P}<0.05$ from respective medium group. e. Effect of L-Arg-P (solid lines) and L-Arg-M (dotted lines) on Swiss normal NIH 3T3 fibroblast cells as evaluated ${ }^{3} \mathrm{H}-\mathrm{Thymidine}$ proliferation assay. Each point is the mean \pm SEM of four replicates of a representative experiment. Three such independent experiments were performed. Key indicates Cell line, Drug and Delivery vehicle $(\mathrm{P})$ in the order separated by a hyphen.

\section{Arg Cures Established Murine Tumors}

Based on the above in vitro data we conducted in vivo experiment to see the therapeutic effect of Arg on murine tumors. We therapeutically administered various drugs in different delivery vehicles. These groups incorporated all the possible controls, to address the issue of volume, $\mathrm{pH}$, hyperosmolarity and chemical environment of the drug delivery schedules. We observed tumor necrosis, shrinkage and dose-dependent tumor cure of solid FS when Arg at $144 \mathrm{mM}(500 \mathrm{mg} / \mathrm{Kg}$ body wt) and $287 \mathrm{mM}(1000 \mathrm{mg} / \mathrm{Kg}$ body wt.) was administered intratumorally either in medium or PBS at the tumor site (Fig. 5a-e). Murine skin at the tumor injection site healed with no scarring (Fig. 5a). We did not observe any systemic toxicity in the Arg-treated mice in all the experimental groups. However, Arg therapy at $200 \mathrm{mM}$ (1050 $\mathrm{mg} / \mathrm{Kg}$ body wt.) cured LSA bearing mice only when delivered in PBS (Fig. 5f-g).

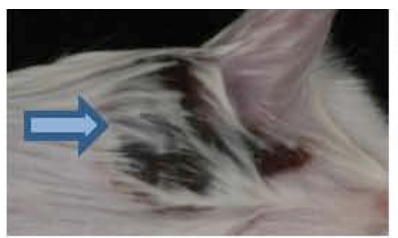

L-Arg-287-P , D10

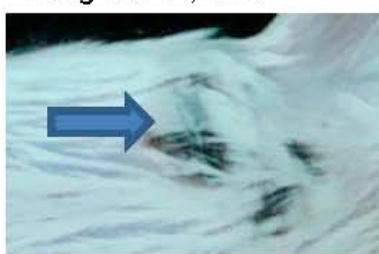

D-Arg-287-M , D10

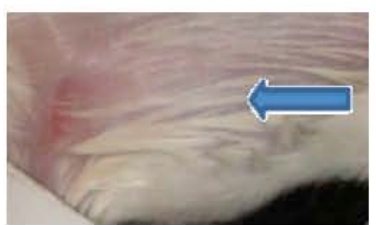

L-Arg-287-P, D30

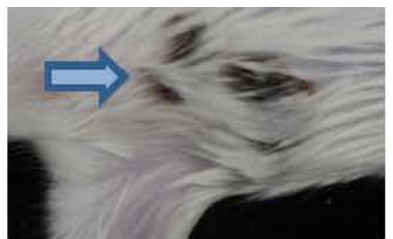

L-Arg-287-M, D10

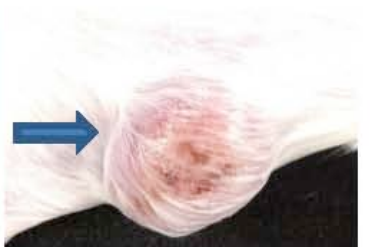

Sham- D10

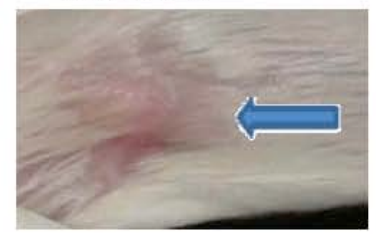

L-Arg-287-M, D30

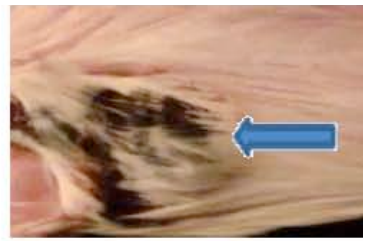

D-Arg-287-P, D10

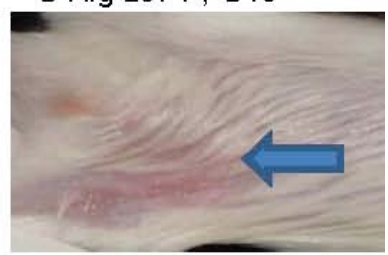

D-Arg-287-M, D30

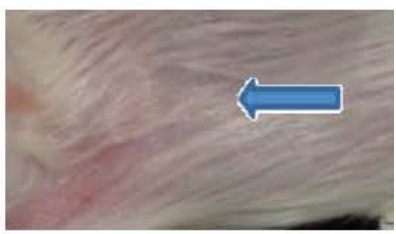

D-Arg-287-P , D30 
(Fig. 5) Contd.....

b

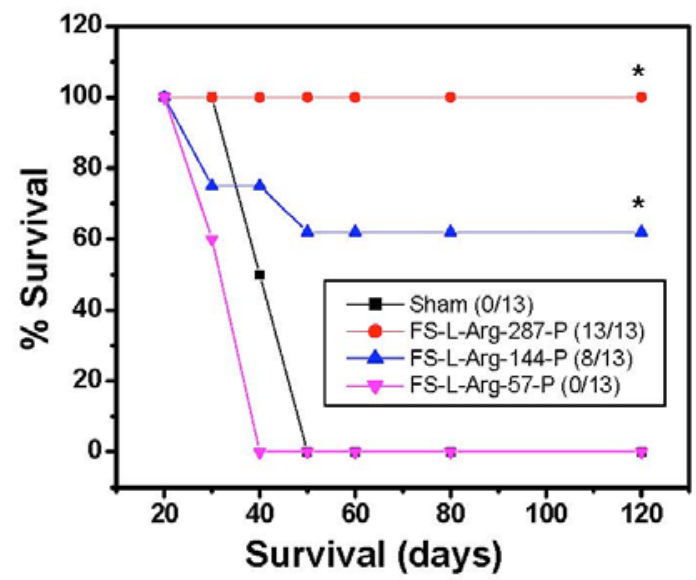

d

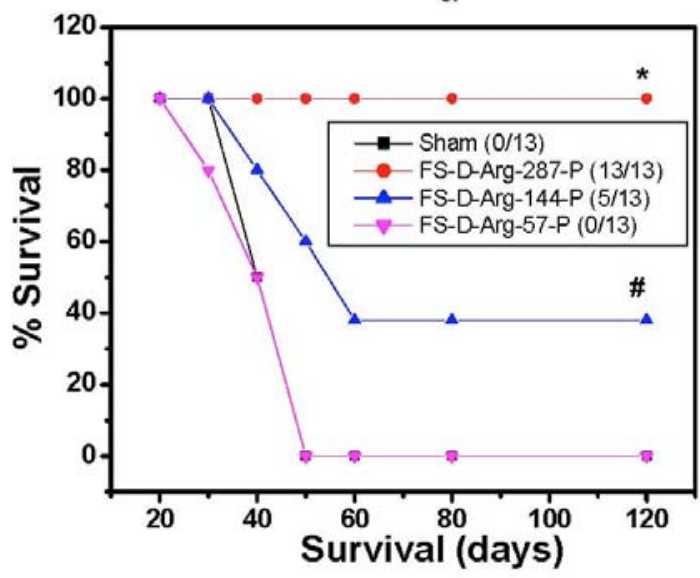

f

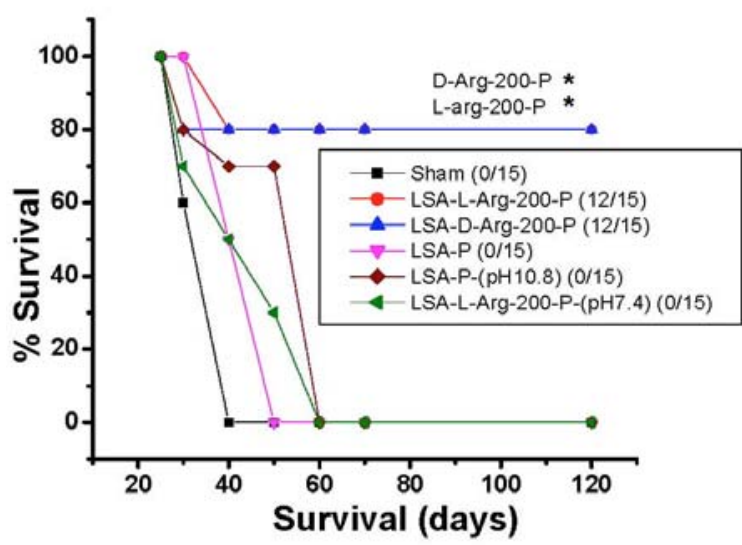

C

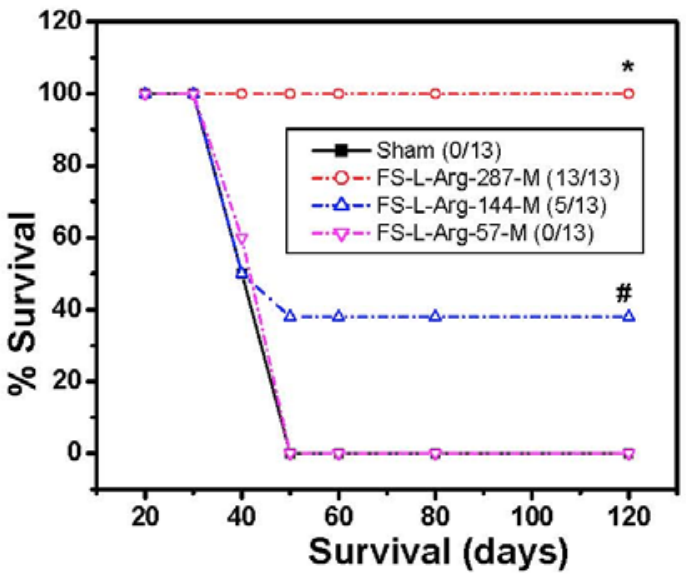

e

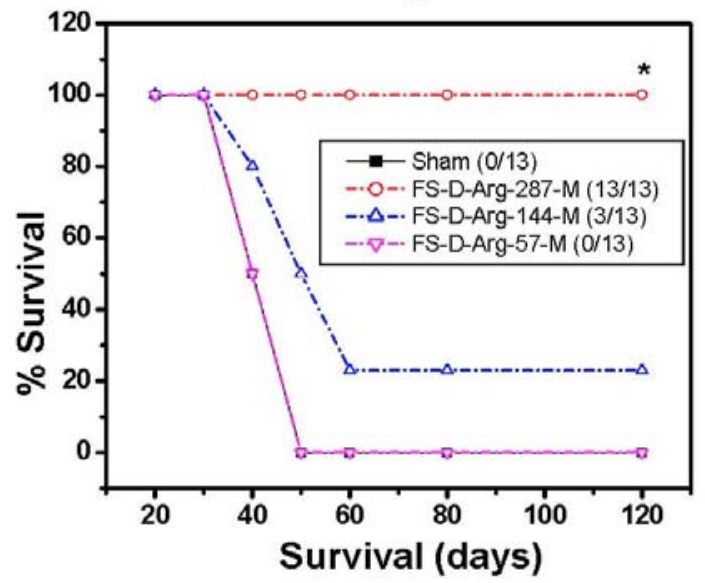

g

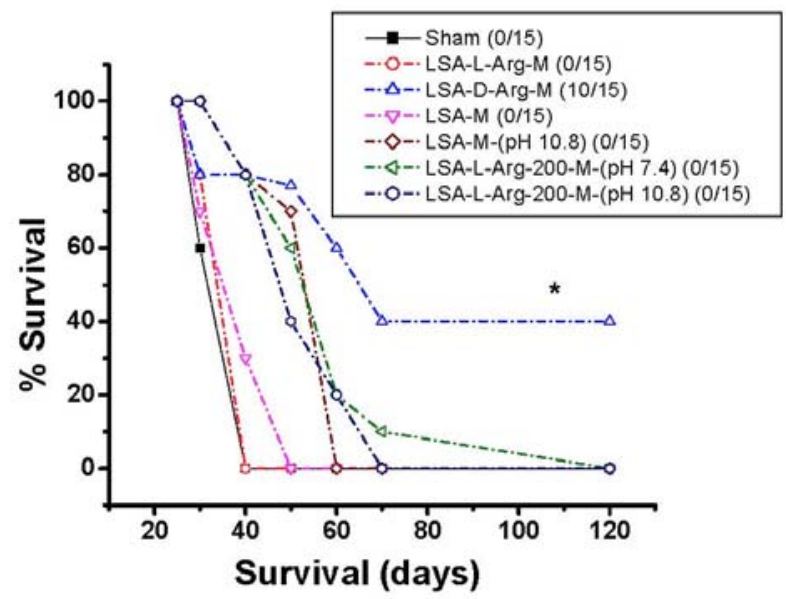

Fig. (5). Anticancer effect of Arg on murine tumors. a. Representative tumor morphology of FS bearing mice treated with Arg-P and Arg.-M, at day 10 and day 30 post tumor transplantation. Arrowheads indicate the area of necrosis. $\mathbf{b}$. Cumulative survival of FS bearing mice treated with L-Arg-P. c. Cumulative survival of FS bearing mice treated with L-Arg-M. d. Cumulative survival of FS bearing mice treated with DArg-P. e. Cumulative survival of FS bearing mice treated with D-Arg-M. Data is pooled from three sets of experiments. f. Cumulative survival of LSA tumor bearing mice, treated with L-Arg-P, D-Arg-P. g. Cumulative survival of LSA tumor bearing mice, treated with L-ArgM, D-Arg-M. Data is pooled from three sets of experiments. The drug delivery schedules are stated with the respective keys. Various drug delivery schedules as abbreviated: Tumor model, Drug, Dose of the drug in $\mathrm{mM}$, Delivery vehicle (P or $\mathrm{M})$ in the order separated by a hyphen. The delivery schedules in which $\mathrm{pH}$ was adjusted is stated in the parentheses. The other parenthesis represents the fraction of total number of tumor free mice $v s$. total number of mice inoculated with tumor. Tumor survival: ${ }^{\#} \mathrm{P}<0.05$; ${ }^{*} \mathrm{P}<0.01$ compared to sham group. 
a

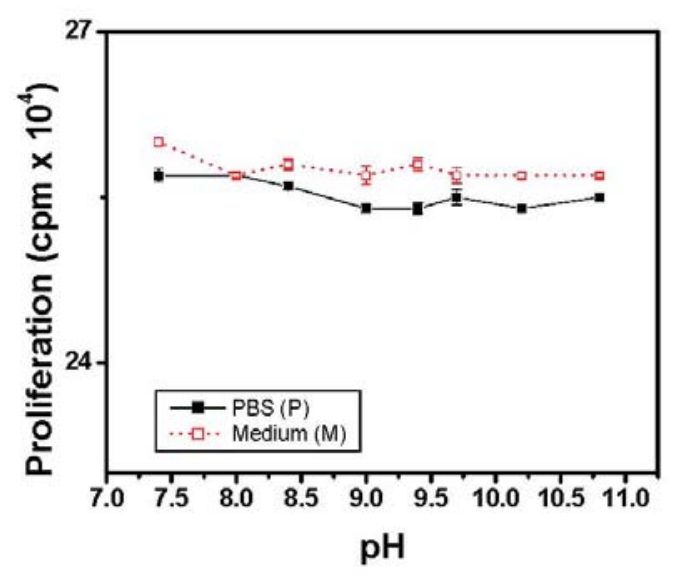

b

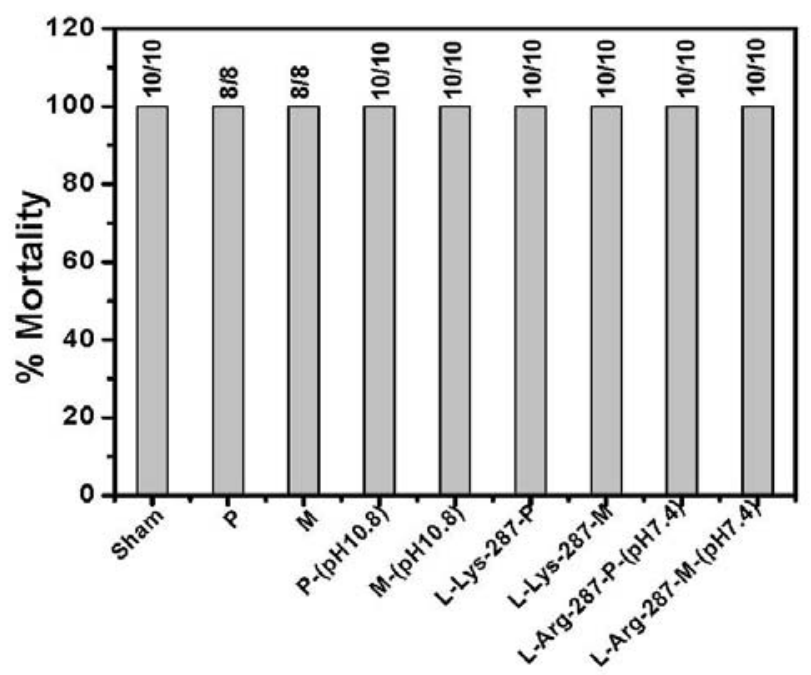

Fig. (6). Effect of delivery vehicle at various alkaline $\mathrm{pH}$ and L-Lys on tumor cells. a. In vitro: Effect of $\mathrm{P}$ (solid lines) and $\mathrm{M}$ (dotted lines) of various alkaline $\mathrm{pH}$ on the proliferation of tumor cells evaluated by ${ }^{3} \mathrm{H}$-Thymidine-based cell proliferation assay. Each point is the mean \pm SEM of six replicates of a representative experiment. Three such independent experiments were performed. b. In vivo: the effect of delivery vehicles at alkaline $\mathrm{pH}$ and L-Lys injected intratumorally as indicated in the graph. Data is pooled from three sets of experiments and represented as a fraction of the total number of mice died of tumor $v s$. total number of mice inoculated with FS tumor. Key indicates various drug delivery schedules as abbreviated: Drug, Dose of the drug in $\mathrm{mM}$ and Delivery vehicle (either P or M) in the order separated by a hyphen. Wherever $\mathrm{pH}$ adjusted is stated in the parenthesis.

\section{Delivery Vehicle at Alkaline $\mathrm{pH}$ and L-Lysine is Not Toxic to Tumor Cells}

Arg is an alkaline amino acid with a pI of 10.8 (the highest among amino acids), which means some characteristics of Arg aqueous solutions are similar to those of alkaline solution. Since $\mathrm{pH}$ of Arg solution is a function of its concentration and delivery vehicle (Table 2), experiments were designed to see the effect of $1 \mathrm{~h}$ of incubation of tumor cells either in PBS or medium at various $\mathrm{pH}$ on the survival of tumor cells. The $\mathrm{pH}$ of the medium or PBS were adjusted using $1 \mathrm{~N} \mathrm{NaOH}$. The survival of tumor cells was monitored by ${ }^{3} \mathrm{H}$-thymidine based proliferation assay. The results indicated that PBS or medium treatment without Arg supplementation at all the $\mathrm{pH}$ did not kill the tumor cells and

Table 2. pH of Various L-Arg Solutions either in PBS or Medium

\begin{tabular}{|c|c|c|c|}
\hline Drug & Concentration (mM) & PBS & Medium \\
\hline \hline L-Arg & 0 & 7.4 & 7.4 \\
\hline L-Arg & 2.5 & 8.4 & 7.5 \\
\hline L-Arg & 5 & 9.2 & 7.6 \\
\hline L-Arg & 10 & 9.6 & 7.8 \\
\hline L-Arg & 20 & 9.7 & 8.3 \\
\hline L-Arg & 50 & 10.2 & 9.3 \\
\hline L-Arg & 150 & 10.5 & 9.7 \\
\hline L-Arg & 300 & 10.8 & 10.0 \\
\hline
\end{tabular}

the tumor survival at the alkaline $\mathrm{pH}$ were not significantly different from the survival of tumor cells in PBS at pH 7.4 or medium at $\mathrm{pH} 7.4$ (Fig. 6a). The tumor incidence or mortality in FS tumor bearing mice was not statistically different in mice treated with medium or PBS (without Arg supplementation, $\mathrm{pH}$ 10.8) when compared to the sham group (Fig 6b). Further, there was no significant tumor growth inhibition in all the groups presented in Fig. (6b), as monitored by tumor size when compared to the sham group, indicating that only $\mathrm{pH}$ of the solution does not contribute to the in vivo tumor killing (data not shown). Treatment of FS tumor bearing mice with cationic amino acid L-Lys at $287 \mathrm{mM}(940 \mathrm{mg} / \mathrm{Kg}$ body wt.) did not confer any antitumor effect (Fig. 6b). In the case of LSA tumor treated with either medium or PBS (without Arg supplementation, $\mathrm{pH}$ 10.8), the survival of mice was not statistically different when compared to the sham group indicating that only $\mathrm{pH}$ of the solution does not contribute to the in vivo tumor killing (Fig. 5f-g). Since L-Arg solution is hyperosmolar, we also investigated the effect of hyperosmolarity on the in vivo anticancer effect of either in PBS or medium. In the case of FS, the osmolarity was adjusted by adding $143 \mu$ moles $\mathrm{NaCl} / \mathrm{ml}$ of either PBS or medium to make osmotic pressure equivalent to $287 \mathrm{mM} \mathrm{L}$-Arg solution. In the case of LSA the osmolarity was adjusted by adding $100 \mu$ moles $\mathrm{NaCl} / \mathrm{ml}$ of either PBS or medium to make osmotic pressure equivalent to $200 \mathrm{mM} \mathrm{L}-\mathrm{Arg}$ solution. The results indicated that these hyperosmolar solutions of either PBS or medium did not have any anticancer effect (data not shown).

\section{DISCUSSION}

The existing cancer therapies can work in two ways, either by induction of apoptosis or by necrosis. Arg when incubated in medium for 24-72 $\mathrm{h}$ had been shown to kill gastric cancer cells through apoptosis [6,7]. All the earlier 
studies suggested the ability of Arg to modify the tumor growth based on the metabolism of Arg [1-4, 6, 7]. Considering that $\mathrm{Km}$ values for the NOS enzymes for Arg are less than $20 \mu \mathrm{M}$, the enzymes will be saturated with the substrate in the tissues culture conditions, as the concentration of L-Arg in tissue culture conditions is more than $1 \mathrm{mM}$. At $5 \mathrm{mM}$ of Arg, the substrate for the NOS enzymes is not a limiting factor, but still we did not get an anticancer effect at these concentrations when Arg was delivered either in PBS or medium. We obtained the anticancer effect only at $10 \mathrm{mM}$ Arg when delivered in PBS. The anticancer effect observed by us is through a nonmetabolic process, since both enantiomers of Arg in PBS at doses less than $50 \mathrm{mM}$ damage the tumor cell membrane. Since LSA tumor cells treated with $10 \mathrm{mM}$ of Arg in PBS environment does not produce NO in the supernatant (Fig S4), Arg pathway via the enzyme NOS does not seems to contribute to the anticancer effect of Arg. Since D-Arg is equally effective as an anticancer molecule both in vitro and in vivo and the enzyme NOS is stereospecific for the Lisomer, these results suggest that the phenomenon is not metabolically driven. Even anticancer peptides having D-Arg is equally effective in killing tumor cells [11]. L-NAME and D-NAME are structural analogues of L-Arg and D-Arg respectively. These structurally analogous moieties can competitively inhibit the binding of Arg to tumor cell membrane and prevent clumping (Fig S3), induced by either L-Arg or D-Arg. Our results (Table 1, Fig. 2a-h) also indicate that necrosis is the most likely mechanism by which Arg inhibited the growth of tumor cells. Further, our data employing PI staining, annexin-V FITC staining, and CRA (Fig. 2a-h) pointed that the mechanism of cell killing is via membrane damage leading to necrosis. This was substantiated by the absence of caspase 3 activity in Arg treated tumor cells. These results indicate that Arg induced tumor cell death seems to be due to physicochemical interaction of pharmacological dose of Arg with tumor cell membrane.

Since primary tumor tissue microenvironment is a critical determinant of the response of tumor cells to the therapy, we selected FS, a solid tumor [26, 27] to demonstrate the ability of Arg to cure the tumor in vivo. We also selected ascitic LSA which mimics the clinical setting of the intra-peritoneal chemotherapy used in ovarian cancer [28]. These tumors syngeneic to the Swiss mice are good loco-regional chemotherapy models, where pharmacological concentrations of Arg in the desired vehicle can be delivered directly into the tumor site. To deliver high doses of drug to target sites with minimal toxicity to non-target organs or tissues, locoregional tumor therapy is an attractive approach for therapy of solid, non-resectable tumors. Loco-regional tumor chemotherapy has low systemic toxicity accompanied by increased therapeutic effect [29]. We selected Arg concentration of 287 $\mathrm{mM}$ at a dose of around $1000 \mathrm{mg} / \mathrm{kg}$ body wt. to treat established murine tumors based on the human pharmacology data on Arg, where $600 \mathrm{mM}$ of L-Arg is injected intravenously for the insulin release assay [30]. Assuming uniform distribution of the Arg injected, the systemic levels of Arg in the mice would be less than $6 \mathrm{mM}$. Since $16 \mathrm{mM}$ of Arg levels were detected with Arg infusion of human beings [31] the doses selected in our studies are pharmacologically relevant. Considering that we are dealing with loco-regional chemotherapy models, Arg concentrations higher than $300 \mathrm{mM}$ can be delivered safely without causing systemic toxicity [29, 30, 32]. Continuous infusion of Arg in saline over a period of time, instead of bolus injection, as used in our studies, may be more effective in treating tumor. Our results indicate for the first time that pharmacological doses of Arg depending on the delivery environment can be used for loco-regional tumor therapy with minimal damage to normal cells. The anticancer property of pharmacological doses of Arg is entirely a new biological function of Arg and could have clinical relevance.

Living systems sense accurately their chemical environments. In our studies Arg-P up to $50 \mathrm{mM}$ decreased the tumor growth in all the four cells lines (Fig. 3a-d), which indicates Arg-P has better tumor inhibitory effect. The IC50 and IC90 values of Arg as shown in Table $\mathbf{3}$ can help in selecting the right chirality, concentration and delivery vehicle for administering Arg in to the tumor site. These results indicated that tumor cells were more sensitive to Arg when delivered in PBS environment. The observation in Fig. (6a) clearly indicated that the tumor cytotoxicity caused by Arg in vitro is not due to alkaline $\mathrm{pH}$ environment of the vehicles, but due to delivering the Arg in free base form. However, L-Arg-M up to $50 \mathrm{mM}$ stimulated the growth of tumor cells. Arg has been demonstrated to either inhibit or facilitate the growth through its metabolism [6,7]. Since the role of polyamines in cell growth, proliferation are demonstrated, Arg via arginase pathway could contribute to the enhanced tumor growth $[1,4,5]$. However, D-Arg when delivered in medium did not facilitate the tumor growth, indicating the advantage of using D-Arg in tumor therapy. In the case of ascitic tumor LSA, Arg cured tumors only when delivered in PBS environment, which correlates with in vitro killing of tumor cells. Since drugs are usually delivered in a saline environment, our studies indicate the need to study the anticancer properties of drugs in saline environment, especially in tumors where dilution of the drug can take

Table 3. The IC50 and IC90 Values of Arg in Various Delivery Vehicle Based on ${ }^{3}$ H-Thymidine Assay

\begin{tabular}{|c|c|c|c|c|c|c|c|c|}
\hline \multirow{2}{*}{ Cell lines } & \multicolumn{4}{|c|}{ IC 50 (mM) } & \multicolumn{3}{c|}{ IC90 (mM) } \\
\cline { 2 - 9 } & L-Arg-P & D-Arg-P & L-Arg-M & D-Arg-M & L-Arg-P & D-Arg-P & L-Arg-M & D-Arg-M \\
\hline \hline LSA & 38.8 & 46.3 & 58.9 & 57.3 & 97.2 & 127.3 & 144.3 & 142.3 \\
\hline FS & 270.7 & 45.5 & - & 119.2 & - & 178.3 & - & - \\
\hline A549 & 41.5 & 132 & 194 & 127 & - & - & - & - \\
\hline MCF7 & 12.8 & 39.4 & 288 & 125 & 29.5 & 149.5 & - & - \\
\hline
\end{tabular}


place. In the case of solid tumor FS, both Arg-P and Arg-M could cause necrosis and eventual elimination of 100 percent of the tumor at a dose of $1000 \mathrm{mg} / \mathrm{Kg}$. For loco-regional therapies demonstration of tumor necrosis is a true indicator of complete response to an antitumor drug [32]. It can be seen from our data that delivery vehicles (PBS or Medium) adjusted to a range of different $\mathrm{pH}$ (7.4 and 10.8) not containing Arg, did not prevent the tumor growth (Fig.6b). Highest concentration of Arg $(287 \mathrm{mM} ; 1000 \mathrm{mg} / \mathrm{kg})$ at $\mathrm{pH}$ 7.4 , injected at the tumor site did not cure the tumor (Fig 6b). However, same (287 mM; $1000 \mathrm{mg} / \mathrm{kg})$ or lower concentrations of Arg (144 mM; 500mg/kg) free base, which has an alkaline $\mathrm{pH}$ delivered into the tumor site, caused the tumor inhibition (Fig. 5b-d). Only free base Arg in PBS, which has an alkaline $\mathrm{pH}$, cured both the murine tumors. Although the IC90 values of Arg for FS in vitro are higher, the delivery of $144 \mathrm{mM}$ of $\operatorname{Arg}(500 \mathrm{mg} / \mathrm{kg})$ into the solid tumor has significant anticancer effect. Positively charged molecules extravasate faster in solid tumors and also cleared from the plasma at a faster rate [33]. Even assuming enhanced Arg delivery to normal organs, the levels or Arg in normal tissues would be much less than $16 \mathrm{mM}$, when $1000 \mathrm{mg} / \mathrm{Kg}$ of L-Arg is administered at the tumor site. At these concentrations, Arg will not contribute to toxicity towards the normal organs [30, 31]. Further, our results (Fig. 4) suggest the lack of toxicity of $50 \mathrm{mM}$ of L-Arg towards normal cells, when exposed for $1 \mathrm{~h}$. These results suggest that Arg at the right dose becomes an ideal anticancer molecule for targeting the solid tumor. Based on the above information, we feel that optimum concentration of Arg could be easily achieved in the solid tumor resulting in a better anticancer effect of Arg in the solid tumor. Our data indicate that both enantiomers of Arg at pharmacological doses depending on the delivery environment cured mice bearing ascitic LSA and solid FS tumor suggesting that Arg interacts with achiral components of the cell membrane and does not appear to proceed via a receptor-mediated route.

ACPs and CAPs interact with negatively charged cell membrane and kill cells usually by a cell membrane-lytic effect $[11,14]$. There are several mechanisms of membranedisruption proposed to explain the activity of ACPs and CAPs. Some of the models used to identify the membranedisrupting process are carpet model, barrel-stave model, toroidal-pore wormhole model and detergent-type membrane lytic mechanism [11, 14]. A direct damage of mitochondria by the ACPs has also been suggested to explain cytotoxic activity ACPs [16]. Our results indicate that the membrane damage caused by Arg, especially when delivered in PBS, could be contributed by similar mechanisms. Formation of large mat of tumor cells suggests extensive cell damage as reflected by significantly reduced cell proliferation (Fig. $\mathbf{2 g}$ and Fig. 3a-d). Large charged residues like Arg contain both lipophilic and aliphatic portion as well as a charged hydrophilic guanidinium group $[18,19,34]$ and that their high $\mathrm{pKa}$ values ensure that they do remain protonated even at alkaline $\mathrm{pH}$. The concentration, geometry, protonation state, high amphiphilic values, charge distribution and the ability to form multiple $\mathrm{H}$-bonds at the ideal local environment could make Arg an anticancer molecule [35]. Arg molecule in dilute solutions is in a zwitterionic form having a large dipole moment, while it tends to be aggregated containing more than two Arg molecules and become non-polar in a con- centrated solution above $10 \mathrm{mM}$ [19]. We also observed Arginduced tumor killing at a concentration of $10 \mathrm{mM}$ and above. Arg presents a hydrophobic environment and exists as molecular clusters in solutions and forms supramolecular assembly in PBS in a dose dependent manner up to $0.5 \mathrm{M}$ and display a hydrophobic surface by the alignment of its three methylene groups $[18,19]$. The clustering was dependent on the solution conditions. Arg solution at $200 \mathrm{mM}$ concentration and a $\mathrm{pH}$ of 10.5 exhibits extensive noncovalent protonated clusters containing more than five Arg molecules, which may contribute to the membrane disruption, leading to necrosis [18]. Arg homo-polymers with more than five amino acids are effective as peptides, in entering the cells [12]. The anticancer property of Arg and its ability to form clusters seem to be correlated, as low concentrations of Arg where clusters were not seen do not prevent tumor cell proliferation. Based on the above data and our results we can hypothesize that Arg interaction with tumor target cell surface is a complex function of Arg concentration, its chemical structure and local environment.

L-Lys, a cationic amino acid like Arg and agmatine, the decarboxylated metabolic product of Arg containing guanidine group did not cause clumping of the tumor cells when delivered in PBS. Amino acid lysine could not replace Arg in its ability to inhibit growth of FS tumor, indicating that cationic nature of the amino acid alone was not sufficient for the efficient anticancer activity. Short oligomers of L-Arg or D-Arg containing six or more amino aids entered far more effectively than polymers of equal length composed of lysine [12]. Arg had higher propensity to form clusters than any other amino acids containing aliphatic chain or many methylene groups [18]. This unique property of Arg at alkaline $\mathrm{pH}$ stems from the strong interactions between their guanidinium and carboxylate groups of adjacent molecules, leading to the formation of Arg clusters. Aggregates of small molecules and not the monomeric forms are the biologically active entities [18]. We believe that a critical threshold of these Arg aggregates at the membrane could cause membrane disruption as suggested for CAP-induced membrane permeabilization [11]. The results suggest the possible role of supramolecular clusters of Arg as the active anticancer agent even though no direct evidence for such clusters is presented in the current work.

Evaluation of side effects of a putative anti-cancer agent is an important aspect of development of therapeutic drugs. Parameters important for the selection of an anticancer drug include its low cytolytic activities to normal mammalian cells and erythrocytes. The cytotoxicity of Arg was selective to tumor cells, as we did not observe Arg-induced cell damage when L-Arg in PBS was incubated with NIH 3T3 cells, lymphocytes or erythrocytes (Fig. 4a-e). Arg did not cause any immunotoxicity as demonstrated by the inability of Arg to prevent Con-A induced T cell proliferation (Fig. 4d). In fact, $1 \mathrm{~h}$ treatment with $50 \mathrm{mM}$ of L-Arg stimulated the growth of Con-A stimulated murine T cells. RBC, which are known to normally maintain a relatively low membrane potential resist the membrane permeabilization by ACPs [16]. It has been suggested that cancer cells, having higher plasma membrane potential than normal cells, are more sensitive to CAPs [16]. Our results suggest that Arg targeted a surprisingly but clearly a fundamental difference in the membrane pattern present predominantly on the tumor cell 
surface and not normal cells, when Arg was delivered at the right dose and environment. Further investigation that combine biophysical and biochemical methods are needed to determine the primary molecular targets on the cell membrane and early plasma membrane events responsible for the Arg induced tumor cell death.

There has been no anti-cancer formulation so far, which is effective for the treatment of cancer using an endogenous molecule. Membrane disruptive property of Arg observed by us should be devoid of the propensity for development of drug resistance because of their unique mode of action $[8,9$, 14, 36]. Arg through its metabolism can either inhibit or facilitate tumor proliferation, but the membrane disruptive property of Arg, through a non-metabolic process prevents the development of tumor resistance, as all four cell lines were killed by Arg. Since the current non-substrate antitumor mechanism of Arg does not depend on the proliferative status of the target cell, it could bypass the cellular mechanisms responsible for multidrug resistance. ACPs with antitumor properties have unresolved issues regarding toxicity, stability, production cost and potential immunogenic responses $[11,36]$. Arg is devoid of these shortcomings. Arg is a small molecule which is stable, soluble, bioavailable, least toxic and does not initiate an immune response and whose pharmacodynamics is well characterized [30]. Our results indicate that loco-regional Arg therapy can be considered to treat accessible tumors in patients in the early stage of cancer, who do not have distant metastasis. Recent meta-analyses and randomized trials have demonstrated that improved loco-regional control does indeed impact longterm survival of stage IV breast cancer patients [37]. These results should appeal to clinicians, cancer biologists and drug designers who have followed therapeutic approaches, which spare the host toxicity and the development of drug resistance.

\begin{tabular}{|c|c|c|}
\hline \multicolumn{3}{|c|}{ ABBERVATIONS } \\
\hline ACPs & $=$ & Anticancer Peptides \\
\hline CAPs & $=$ & Cationic Antimicrobial Peptides \\
\hline Arg & $=$ & Arginine \\
\hline L-Arg & $=$ & L-Arginine \\
\hline D-Arg & $=$ & D-arginine \\
\hline $\mathrm{P}$ & $=$ & PBS \\
\hline M & $=$ & Medium \\
\hline L-Lys & $=$ & L-Lysine \\
\hline $\mathrm{MCF}$ & $=$ & Mean corpuscular fragility \\
\hline FS & $=$ & Fibrosarcoma \\
\hline LSA & $=$ & Lymphosarcoma-ascites \\
\hline PBS & $=$ & Phosphate buffered saline \\
\hline ACPs & $=$ & Anticancer peptides \\
\hline CAPs & $=$ & Cationic antimicrobial peptides \\
\hline FCS & $=$ & Fetal calf serum \\
\hline Arg-P & $=$ & Arginine in PBS \\
\hline
\end{tabular}

$$
\begin{aligned}
& \text { Arg-M }=\text { Arginine in medium } \\
& \text { CRA }={ }^{51} \text { Chromium release assay }
\end{aligned}
$$

\section{ACKNOWLEDGEMENTS}

The project was completely funded by Bhabha Atomic Research Centre, Government of India. The authors sincerely acknowledge Dr Ashok Hadapad of NABTD for statistical analysis; Ms. Priyanka J. Reddy and Ms. Sonali P.D. Bhade of Radiation Safety and System Division for radioactive counting; Mr. Mansoor Ali and Ms. Vasumathy for technical assistance in confocal microscopy; Mr. KS Munankar and NS Sidnalkar for their useful technical assistance.

\section{SUPPLEMENTARY MATERIAL}

Supplementary material is available on the publishers Web site along with the published article.

\section{REFERENCES}

[1] Grillo MA, Colombatto S. Arginine revisited: minireview article. Amino Acids 2004; 26: 345-51.

2] Lind DS. Arginine and cancer. J Nutr 2004; 134: 2837-41.

[3] Tong BC, Barbul A. Cellular and physiological effects of arginine. Mini Rev Med Chem 2004; 4: 823-32.

[4] Wu G. Amino acids: metabolism, functions and nutrition. Amino Acids 2009; 37: 1-17.

[5] Agostinelli E, Bachrach U. Polyamines and their analogs in cancer and other diseases. Amino Acids 2007; 33: 173.

[6] Nanthakumaran S, Brown I, Steven DH, Schofield AC. Inhibition of gastric cancer cell growth by arginine: Molecula mechanisms of action. Clin Nutr 2009; 28: 65-70.

[7] Wolf C, Bruss M, Hanisch B, et al. Molecular basis for the antiproliferative effect of agmatine in tumor cells of colonic, hepatic and neuronal origin. Mol Pharmacol 2007; 71: 276-83.

[8] Schweizer F. Cationic amphiphilic peptides with cancer-selective toxicity. Eur J Pharmacol 2009; 625: 190-4.

[9] Bhutia SK, Maiti TK. Targeting tumors with peptides from natural sources. Trends Biotechnol 2008; 26: 210-7.

[10] Chabner BA, Roberts TG, Jr. Chemotherapy and the war on cancer. Nat Rev Cancer 2005; 5: 65-72.

[11] Hoskin DW, Ramamoorthy A. Studies on anticancer activities of antimicrobial peptides. Biochem Biophy Acta 2008; 1778: 357-75.

[12] Dandan Y, Guoming L, Gao L, Wei L. Interaction of arginine oligomer with model membrane. Biochem Biophys Res Commun 2007; 359: 1024-9.

[13] Dennison SR, Whittaker M, Harris F, Phoenix DA. Anticancer alpha-helical peptides and structure/function relationships underpinning their interactions with tumor cell membranes. Curr Protein Pept Sci 2006; 7: 487-99.

[14] Mader JS, Hoskin DW. Cationic antimicrobial peptides as novel cytotoxic agents for cancer treatment. Expert Opin Investig Drugs 2006; 15: 933-46.

[15] Zasloff M. Antimicrobial peptides of multicellular organisms. Nature 2002; 415: 389-95.

[16] Lemeshko VV. Potential-dependent membrane permeabilization and mitochondrial aggregation caused by anticancer polyarginineKLA peptides. Arch Biochem Biophys 2010; 493: 213-20.

[17] Janin YL. Peptides with anticancer use or potential. Amino Acids 2004; 25: 1-40

[18] Das U, Hariprasad G, Ethayathulla AS, et al. Inhibition of protein aggregation: Supramolecular assemblies of arginine hold the key. PLoS One 2007; 11: e1176.

[19] Toyama N, Kohno J, Mafune F, Kondow T. Solvation structure of arginine in aqueous solution studied by liquid beam technique. Chem Phys Lett 2006; 419: 369-73.

[20] Shukla Jyoti, Thakur VS, Poduval TB. Arginine magic: Arginine kills tumor cells when presented in saline. FASEB J 2008; 22: 1198.5 . 
[21] Thakur VS, Shankar B, Chatterjee S, Premachandran S, Sainis KB. Role of tumor-derived transforming growth factor- $\beta 1$ (TGF- $\beta 1$ ) in site-dependent tumorigenicity of murine ascitic lymphosarcoma. Cancer Immunol Immunother 2005; 54: 837-47.

[22] Poduval TB, Seshadri M, Sundaram K. Lectin potentiation of BCGcontact-mediated antitumor action. J Natl Cancer Inst (Bethesda) 1984; 65: 909-12.

[23] Zons Von P, Crowley-Nowick P, Friberg D, et al. Comparison of europium and chromium release assays: cytotoxicity in healthy individuals and patients with cervical carcinoma. Clin Diagn Lab Immunol 1997; 2: 202-7.

[24] Chatterjee S, Premachandran S, Bagewadikar RS, Poduval TB. The use of ELISA to monitor amplified hemolysis by the combined action of osmotic stress and radiation: potential applications. Radiat Res 2005; 163: 351-5.

[25] Ailenberg M, Silverman M. Differential effects of trichostatin A on gelatinase A expression in 3T3 fibroblasts and HT-1080 fibrosarcoma cells: implications for use of TSA in cancer therapy. Biochem Biophy Res Commun 2003; 302: 181-5.

[26] Cairns R, Papandreou I, Denko N. Overcoming physiologic barriers to cancer treatment by molecularly targeting the tumor microenvironment. Mol Cancer Res 2006; 4: 61-70.

[27] Minchinton AI, Tannock IF. Drug penetration in solid tumors. Nat Rev Cancer 2006; 6: 583-92.

[28] Fung-Kee-Fung M, Provencher D, Rosen B, et al. Intraperitoneal chemotherapy for patients with advanced ovarian cancer: a review of the evidence and standards for the delivery of care. Gynecol Oncol 2007; 105: 747-56.
[29] Celikoglu F, Celikoglu SI, Goldberg EP. Bronchoscopic intratumor chemotherapy of lung cancer. Lung Cancer 2008; 61: 1-12.

[30] Boger RH, Bode-Boger SM. The clinical pharmacology of Larginine. Annu Rev Pharmacol Toxicol 2001; 41: 79-99.

[31] Marietta M, Facchinetti F, Neri I, Piccinini F, Volpe A, Torelli G. L-arginine infusion decreases platelet aggregation through an intraplatelet nitric oxide release. Thromb Res 1997; 88: 229-35.

[32] Forner A, Ayuso C, Varela M, et al. Evaluation of tumor response after locoregional therapies in hepatocellular carcinoma: are response evaluation criteria in solid tumors reliable? Cancer 2009; 115: 616-23.

[33] Dellian M, Yuan F, Trubetskoy VS, Torchilin VP, Jain RK. Vascular permeability in a human tumor xenograft: molecular charge dependence. Br J Cancer 2000; 82: 1513-8.

[34] Gruber J. Analysis of hydrophobic potential on molecular surfaces. Laboratory of Molecular Biophysics 2000. Available from: http://biop.ox.acuk/www/lj2000/noble_02.html

[35] Mitaku S, Hirokawa T, Tsuji T. Amphiphilicity index of polar amino acids as an aid in the characterization of amino acid preference at membrane-water interfaces. Bioinformatics 2002; 18 : 608-16.

[36] Strom MB, Haug BE, Skar ML, et al. The pharmacophore of short cationic antibacterial peptides. J Med Chem 2003; 46: 1567-70.

[37] Bevan HL, Nguyen NP, Vinh-Hung V, Rapiti E, Vlastos G. Locoregional treatment in metastatic breast can patients: Is there a survival benefit? Breast Cancer Res Treat 2010; 119: 537-45.

This is an open access article licensed under the terms of the Creative Commons Attribution Non-Commercial License (http://creativecommons.org/licenses/by$\mathrm{nc} / 3.0 /$ ), which permits unrestricted, non-commercial use, distribution and reproduction in any medium, provided the work is properly cited. 